\title{
التوجهات الثمانية لأهداف الإنجاز للدى طلاب المرحلة الإعدادية
}

$$
\text { إعداد }
$$

/ فاطمه عبدالمنعم محمد ابراهيم

$$
\begin{aligned}
& \text { باحثة ماجستير } \\
& \text { بكلية التربية بقنا - جامعة جنوب الو أدي } \\
& \text { fatmaabdelmoneam8@gmail.com }
\end{aligned}
$$




\title{
التوجهات الثمانية لأهداف الإنجاز للدى طلاب المرحلة الإعدادية
}

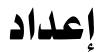 \\ / فاطمه عبدالمنعم محمد ابراهيم \\ باحثة ماجستير \\ بكلية التربية بقنا - جامعة جنوب التو ادي \\ fatmaabdelmoneam8@gmail.com
}

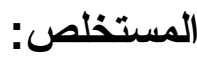

هدف البحث الحالي إلى اكتثاف التوجهات الثمانية لأهداف الإتجاز لاى طلاب المرحلة الإعدادية، وتألفت عينة البحث الأساسبة دن (T1 الطالبًا وطالبة)،

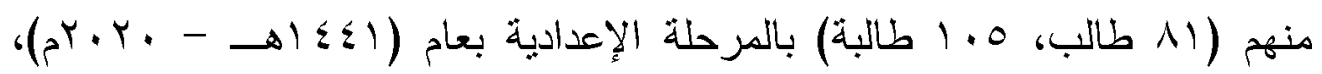
واستخدم البحث الأداة: مقياس التوجهات الثمانبة لأهداف الإنجاز (إعداد

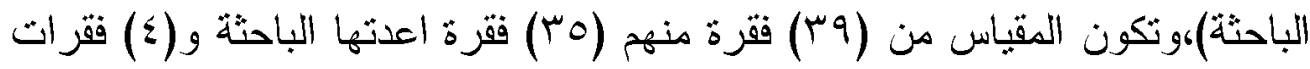
عن ثوجه (إحجام-ذات المستقبل) أعدها حجاج غانم(في هذا البحث)، ولمعالجة فرض البحث ثم استخدام الاسالبب الإحصائية التالية: اختبار "ت" للعينة الواحدة وأحجام التأثير، ولقد ثم استخدام برنامج SPSS 23 لتنفيذ هذه الاساليب الإحصائية، و النتائج الثي ثم الثوصل إليها: أن عينة البحث تثسم بمسنويات مرتفعة من الثوجهات الثمانية لأهداف الإنجاز، وتم تقديم بعض الثوصبات بناءً على ثلاك النتيجة. الكلمات المفتاحية: الثوجهات الثمانبة لأهداف الإنجاز - طلاب المرحلة الإعدادية 
التوجهات الثماتية لأهداف الإنجاز لاى طلاب المرحلة الإعدادية

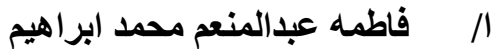

\title{
The eight orientations of achievement goals for the middle school pupils
}

\author{
Fatma Abd elmoneam Mohammed Ibrahim \\ Researcher for master's \\ Faculty of Education - South Valley University \\ fatmaabdelmoneam8@gmail.com
}

\begin{abstract}
:
The present research aimed to identify the eight orientations of achievement goals among the middle school pupils. The basic research sample consisted of (186) male and female students, including (81 male , 105 female) students of the middle school in the year (1441 AH 2020 AD). The research used the following tool: The measure of the eight orientations of achievement goals (prepared by the researcher). The measure consisted of (39) items, including (35) items prepared by the researcher and (4) itemsonthe orientation of (Self potentialavoidance) prepared by Hagag Ghanem (inthis research). In the research hypothesis, the following statisticalmethods were used: One sample T-test and the effect size to test hypothesis, and the $\operatorname{SPSS}_{23}$ program was used to implement these statistical methods. The results obtained: The research sample is characterized by high levels of the eight orientations of achievement goals. Some recommendations were made based on that result.
\end{abstract}

Keywords: The eight orientations of achievement goals - the middle school pupils. 
طالب العلم يضع لنفسهِ هدفا اوليًا وهو الإنجاز، ولكن لكل طالب مسلك

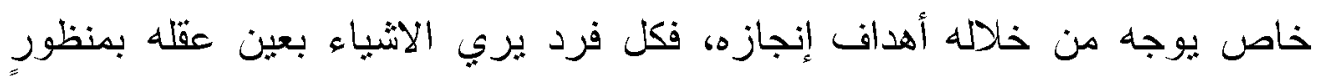
خاص لنحقيق الأهداف المرجوة.

ولتنحقيق هدف الإنجاز لابد من وجود دافعبة لدي المتعلم تدفعه للتعلم، و لأهمية هذا الموضوع تمت دراسات عديدة في مجال الدافعية، حتي انبثق منها مصطلح توجهات أهدات الإنجاز في نهائيات القرن الماضي (القرن العشرين) علي (Ames and Archer,1988; يد مجموعة من الباحثين لعدة بحوث مستقلة منها Dweck and Leggett,1988; Nicholls,1984) ولقد اثشارت جميع نتاجات هذه الابحاث إلى ما سمي بالنموذج الثنائي لتوجهات أهداف الإنجاز بجهنيه توجهات(أهداف الاتقان، أهداف الاداء).

ثم عمل Elliot and Harackiewicz (1996) علي تطوير النموذج الثنائي حيث

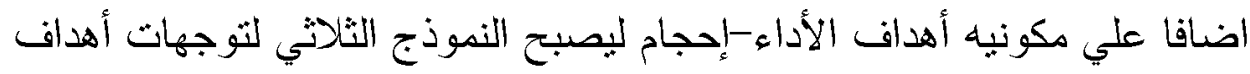

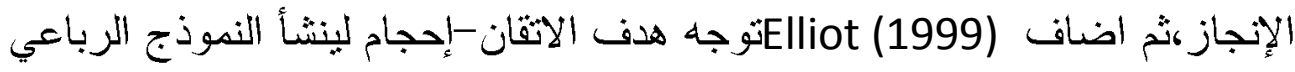
.$(r \times Y)$

وتكاتقت جهود . 2011)Elliot et al) ليخرج النموذج السداسي لتوجهات أهداف

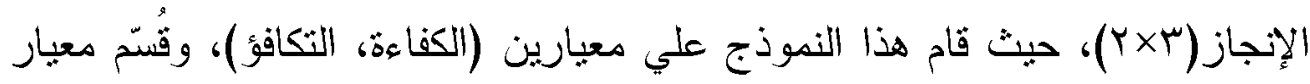
النكافؤ إلى فرعين (الإقدام، الإحجام)، والإقدام: يكون من خلال النهج علي الإيجايية

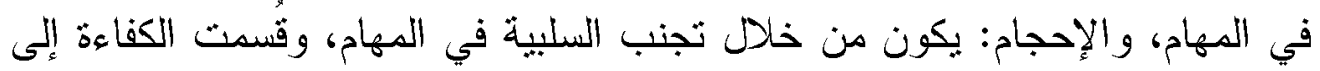

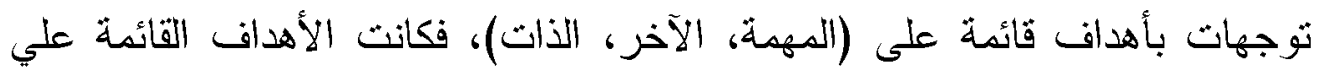

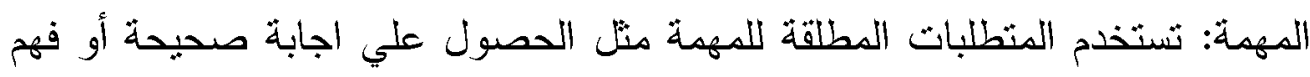

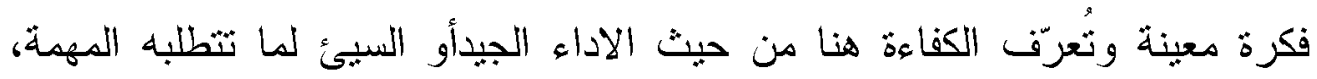

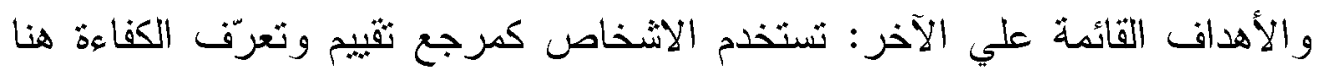


من حبث مقارنة اداء الفرد بشكل جيد أو سيئ بالنسبة لأداء الآخرين، اما الأهداف القائمة علي الذات: تستخدم المسار الشخصي للفرد كمرجع ثقييمي ونعرّت الكفاءة هنا من حيث الأداء بشكل جيد أو سيئ لما قام به الفرد في الماضي أو لديه القدرة علي القيام به في المسثقبل (Elliot et al., 2011).و هنا بكون قد ثم الإلماح بشكل عام لأهداث الذات القائمة علي المستقبل لكن دون تناصبل. حثي اصبحت ثوجهات أهداف الإنجاز حثي الآن ثُمانية علي يد كلًا من Elliot et al. (2015)

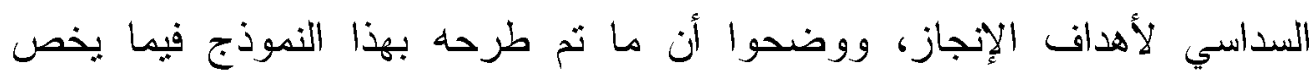
الأهداف الذاتية إنها أهداف قائمة علي الماضي ببندي نكافؤ (إقدام-الماضي،هوإحجامالماضي)، وبنو العي التلميح المُسبق الذي ذكر بالدراسة السابقة أهداف الذات القائمة

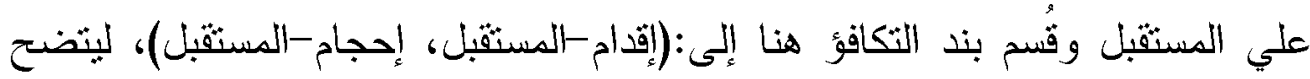
الفصل بين الأهداف المسندة إلى الماضي والأهداف المسندة إلى المسثقبل، ولكن ثم ادر اجهم تحت فئة الأهداف الذاتية، وينم تعريف الأهداف الذاتية هنا بأنها: ثشتخدم المسار الشخصي كمعيار للتقييم وقد يكون هذا المسار من خلال أهداف الذات القائمة علي الماضي أوأهداف الذات القائمة علي المسنقبل، ولكًا منهما معيار نكافؤ ثنائي إقداما وإحجاما؛ لينتج ثمانية ثوجهات أهداف في اطار النموذج السداسي المُقام علي معبار الكفاءة (الآخر، المهمة، الذات)، مع توسيع أهداف الذات في النموذج

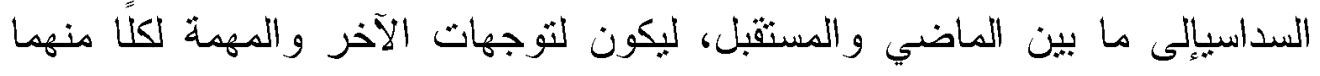
تكافؤ ثنائي التفرع (إقدام-المهمة، إحجام-المهية، إقدام-الآخر، إحجام-الآخر)، والتوجهات الذات نكافؤ رباعي التفرع (إقدام-ذات الماضي، إحجام-ذات الماضي، إقدام-ذات المسثقبل، إحجام-ذات المستقبل)، وهذا بيين لنا علي ما اكدوه في دراسته: نوسيع النموذج السداسي (YXY) في فئة الأهداف الذاتية وشددوا علي إنه

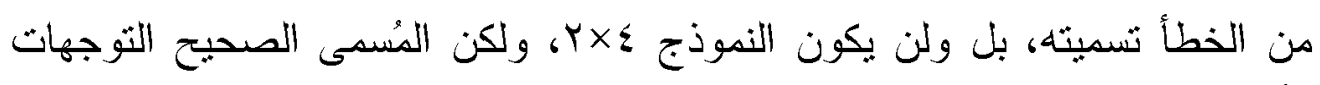
الثُمانبة لأهداف الإنجاز (Elliot et al., 2015). 
ولكن إذا كان كل طالب وجهة خاصة به يسلكها للوصول إلى الإنجاز، فما

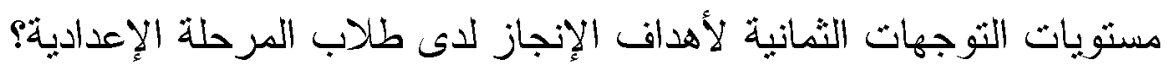

\section{مشكلة|لبحث: - مئ}

تتحدد مشكلة البحث في ثناث محاور رئيسية، فالمحور الاول: يدور حول

اهمية الكثف عن مستويات نوجهات أهداف الإنجاز؛ من حيثية أن عدم إلمام المعلمين وأولياء الأمور بمعرفة هذه المستويات الثي يسلكها الطلاب في السعي الإنهي لتحقيق هدف الإنجاز؛ قد يؤدي لحدوث مشكلة اخرى وهي عدم تجاوب الطلاب مع ما بقدم لهم بالصف الدراسي؛ وبالتالي عدم قدرة الطلاب على الإلمام بمثطلبات الدراسة و الفشل في الإنجاز الدر اسي. لاسئ

أما المحور الثاني لمشكلة البحث: فيظهز من خلال تعدد وجهات النظر بشأن تتاول تصنيفات توجهات أهداف الإنجاز (Elliott and Story, 2017) في النصنيف (Stan and Oprea, 2015) في الثتائي، (Stahin et al., فئيف الثناثي، (2016في التصنيف الرباعي، (Hall et al., 2015)في التصنيف الخماسي،(حجاج

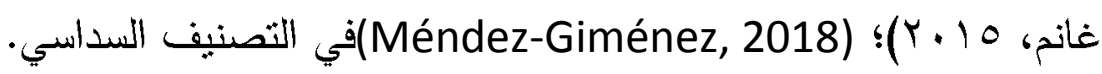
ورغم تعدد البحوث التي نتاولت توجهات أهداف الإنجاز باختلاف تصنيفاتها من الثائية والثلاثية و الرباعية و الخماسية والسداسبة؛ إلا انه لم ثنتطع الباحثة

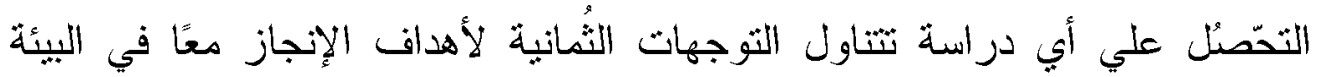

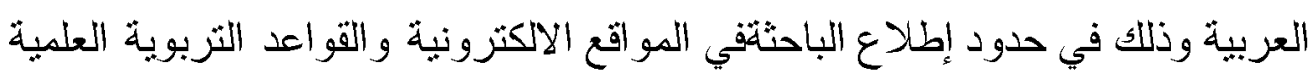
Google) معلومات شمعة التربوية)حتي كتابة البحث الحالي، اما في البيئة الاجنيية فقد وجدت دمات

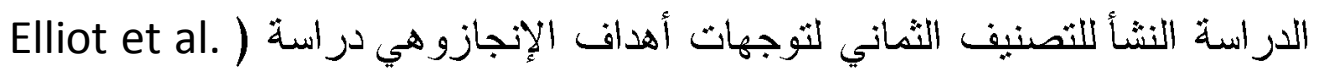
2015,)، ودر اسة اخرى فقط وهي Ning (2017) وتتاولت دراسة مقياس أحدث فرعين فقط منا لتوجهات الثمانية لأهداف الإنجاز (توجه إقدام-ذات المستفبل، ثوجه ودناس 
إحجام-ذات المستثبل)، وذلك لحداثة التصنيف الثماني لثوجهات أهدات الإنجاز وهذا يمثل المحور الثاني لمشكلة البحث، ولذلك فإن هذا البحث يُقدم اول دراسة في الوطن

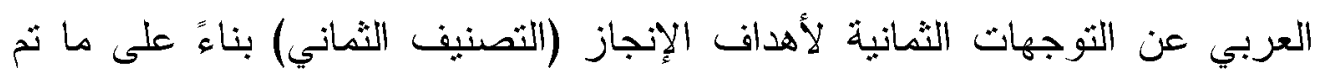
ذكره.

بينما يظهر المحور الثالث لمشكلة البحث: بناءً على المحورين السابقين فحداثة التصنيف الثماني لتوجهات أهداث الإنجاز، والتطرق لأهمية الكثف عن مستو ياته لدى الطلاب؛ بدفع لبناء مقياس يقبس هذه المستويات وتثديمه لإثراء البيئة العلمية، وليككن اون مقياس يقيس التوجهات الثمانية لأهداف الإنجاز في الوطن العربي بناءً على ما نم ذكره مسبقًا.

ومن منطلق كل ما سبق تظهر مشكلة البحث، ويأتي البحث الحالي التوجهات الثمانية

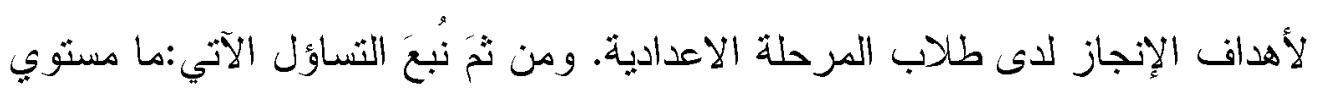
الثوجهات الثمانبة لأهداف الإنجاز لدى طلاب المرحلة الاعدادية؟ أهداف البحث: - n

1- اكتشاف التوجهات الثمانية لأهداف الإنجاز عند طلاب المرحلة الإعدادية. ץ- دعرفة دستويات توجهات أهداف الإنجاز الثمانبة لدى طلاب المرحلة الإعدادية. اهمية البحث: تتمثل اهمية البحث في:

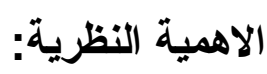
1- حداثة موضوع البحث، فمتغير التوجهات الثمانية لأهداف الإنجاز من المتغيرات الحديثة علميًا فهذه اول دراسة في الوطن العربي تثتاول التصنيف الثماني لتوجهات أهداف الإنجاز (في حدود إطلاع الباحثة في المواقع الإلكثرونبة السابقة الذكر). 
Y- معرفة ثوجهات أهداف الإنجاز بيساهم في معرفة دوافع الطلاب الإنجازية،

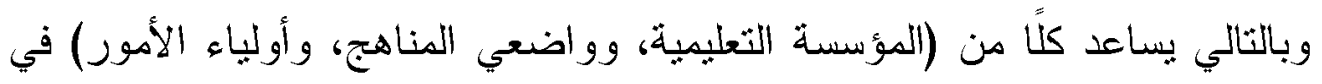
اختبار ات تعليمية تقلل من بُخض الطلاب للبيئة الصفية، وتتجعهم علميًا على الإنجاز

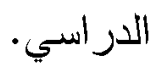

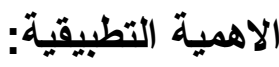

1- ثقديم مقياساً حديثًا للبيئة العلمية عن التوجهات الثمانية لأهداف الإنجاز لخدمة البحث العلمي.

مصطلحات البحث:

التوجهات الثمانية لأهداف الإنجاز:

بعد الاطلاع على الأدبيات السابقة الخاصة بمثغير توجهات أهداث الإنجاز مثل على

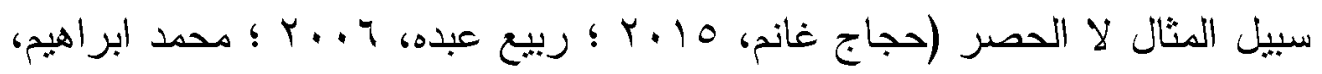
(Dweck and Leggett, 1988 ;Elliot et al., 2011 Elliot et al., ( .2015)

تعرّف الباحثة التوجهات الثماتية لأهداف الإججاز تعريفًا إجرائيًا: بأنها الأسباب

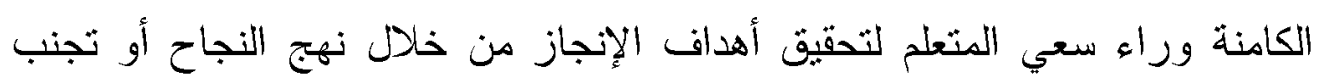
الإخفاق في أداء مواقف الإنجاز، امتثالًا لطبيعة المهمة أو آراء الآخرين أو طبيعة الأنة

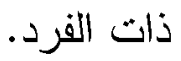

وتعرّف الباحثة تعريفًا إجرائًا لكل توجه من الثوجهات الثمانبة لأهداف الإنجازعلى

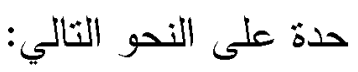
1- توجه إقام-المهمة Task-approach: هو سعي الطالب نحو نهج النجاح في أداء المهمة الدراسية، لإشباع الثغف بتعلم المهمة نفسها أو للتمكن منها. 
r- توجه إحجام-المهمة Task-avoidance: هو سعي الطالب نحو تجنب الاخفاق في أداء المهة الدراسية،لتفادي الثقصبر في تعلمها أو الرسوب فيها. ب- توجه إقدام-الآخر Other-approach : هو سعي الطالب نحو نهج النجاح في أداء المهة الار اسية، لنيل استحسان الآخرين أو التفوق علبهح. צ-توجه إحجام-الآخز Other-avoidance: هو سعي الطالب نحو تجنب الاخفاق في أداء المهمة الدراسية، لتفادي الثعور بالإحراج بين الآخرين، أو الظهور بمظهر الضعف امامهم، أو خذلان املهم في الحصول على الإنجاز.

ه-توجه إقدام-ذات الماضي Self past-approach: هو سعي الطالب نحو نهج النجاح في أداء المهمة الدراسية، لنطويرمستوى القدرة الذاتبة افضل من ما مضى. צ-توجه إحجام-ذات الماضي Self past-avoidance: هو سعي الطالب نحو تجنب الاخفاق في أداء المهمة الدراسية، لتفادي تتاقص مستوى القدرة الذاتية عن ما مضى.

V-توجه إقدام-زات المستقبل Self potential-approach: هو سعي الطالب نحو نهج النجاح في أداء المهمة الدراسبة، باستخدام اقصى ما في إمكاناته واسنطاعته، للارثقاء بمستوى القدرة الذاتية و ازدهار ها مسثقبًا.

^-توجه إحجام-زات المستقبل Self potential-avoidance: هو سعي الطالب نحو تجنب الاخفاق في أداء المهة الدراسية، لتفادي الاداء بمستوى اضعف من مستوى مدى إمكاناثه و استطاعثه في الازثثاء بالقدرة الذاتبة مستثبلً. 
الإطار النظري و الار اسات السابقة وفرض البحث:

اولا : توجهات أهداف الإججاز: إن

عرّت(Elliot et al.توجهات أهداف الإنجاز بأنها تقدم لنا تفسيرًا عن سبب انخراط المتعلم في سلوك الإنجاز، وتثام علي معيارين للتقييم هما الكفاءة

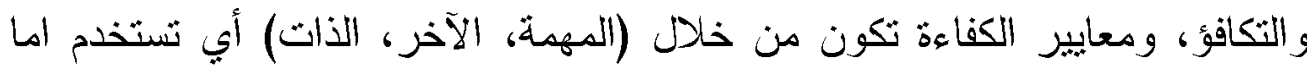

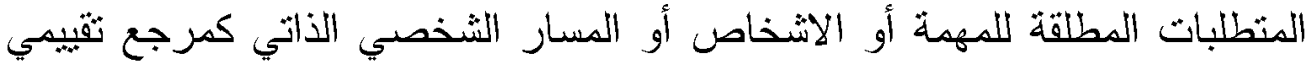

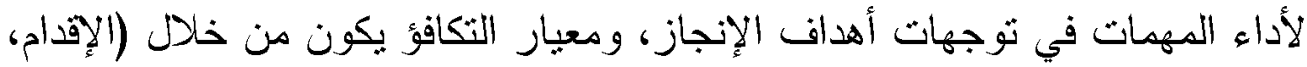
الإحجام)، والإقدام: يكون من خلال النهج علي الإيجايبة في الدهام، والإحجام: يكون الإنان

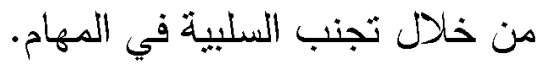
وقبل التطرق للتصنيف الثماني لتوجهات أهداف الإنجاز سنتناول التصنيفات التي عرض تقبله.

من أوائل الدراسات التي بحثت في التوجهات الثائية لأهداف الإنجاز

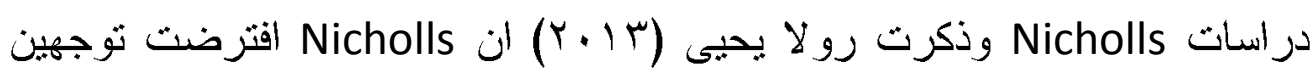

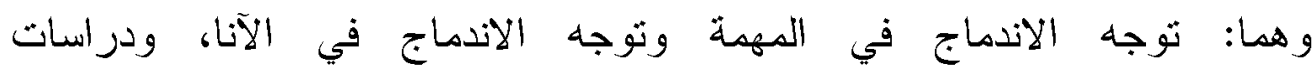
(Dweckandleggett,1988)

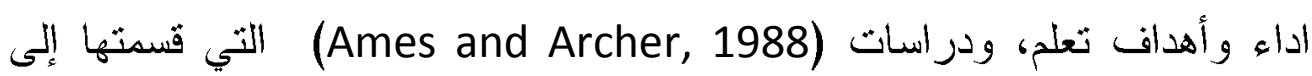

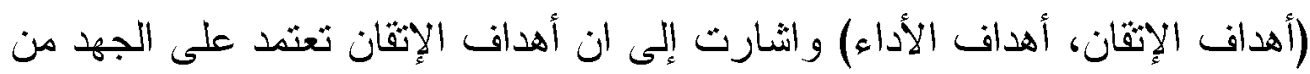
قبل الطلاب؛ وهذه الأهداف تفسر تصورات الطلاب داخل البيئة الصفية عن اختبار

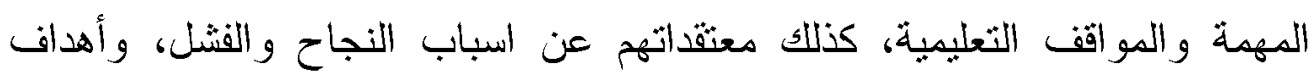

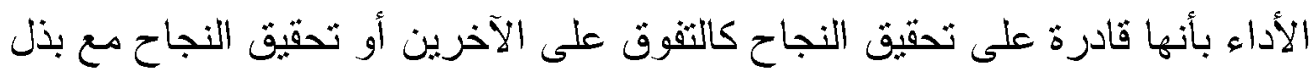

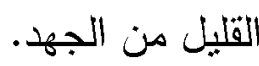

وطور (1996) Elliot and Harackiewicz) التصنيف السابق ليضيف على مكونبه أهداف الأداء-إحجام لينشأ التصنيف الثلاثي لتوجهات أهداف الإنجاز 
بمكوناته (توجه هدف الإثقان، ثوجه هدف الأداء-إقدام، ثوجه هدف الأداء-إحجام)،

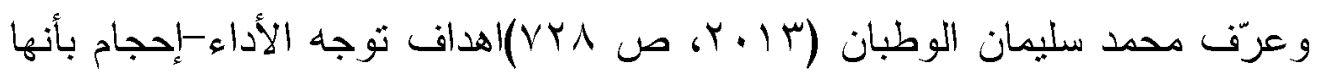
"تزكز علي تجنب عدم الكفاعة المستمدة من الاخر".

ثم اضاف Elliot (1999) أهداف الإتقان -إحجام ليصبح التصنيف رباعيًا فيما سمي بالنموذج الرباعي (YXY) لتوجهات أهداف الإنجاز الإنقان -إقدام،

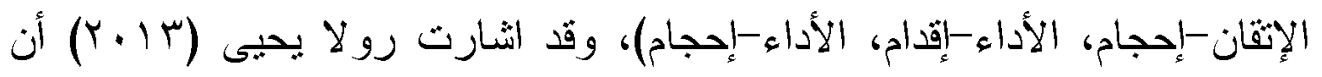
اصحاب الإثقان -إحجام يسعون لتجنب نسبان فكرة تعليمية معينة أو عدم فهم فكرة في درس أو عدم فهم درس معين وذلكل تجنب عدم الفهم في ضوء معايير المهمة أو لعائه المعايير الذاثية.

ولقد أشـار (2014) وان في التصنيف الخماسي لتوجهات أهداف الإنجاز فيه تمث الاضافة علي النموذج الرباعي السالف الذكر توجه هدف خامس اطلق عليه نوجه هدف تجنب-العمل واشاروا إلى ان ثوجه تجنب-العمل يسمي ايضًا الاغتراب الأكاديمي، وان الطلاب الذين يثنبون هذا التوجه لا يهنمون بتطوير الكفاءة أو إظهارها بل يكون لديهم ميل نحو الأداء السيئ في بيئة التعلم. كما قام (2011) بlliot et al. بإنشاء تصنيف سداسي لتوجهات أهداف الإنجاز وهو النموذج السداسي في ما عرفت بثوجهات أهداف الإنجاز السداسية، ونم إلقاء الضوء علي ان أهداف الإثقان تشنمل علي أهداف قائمة علي المهية وأهداف قائمة علي الذات ثم الفصل بينهما من حيثية ان الأهداف القائمة علي المهمة الهية نكون موجهة لفهم جديد المواد الدراسية كاما الأهداف القائمة علي الذات نكون التهن موجهة في توسيع نطاق المعرفة؛ أي ان توجه هدف المهمة وتوجه هدف الذات كلاهما يندرجان تحث عنوان واحد وهو توجه هدف الإتقان، الما توجه هدف الاداء

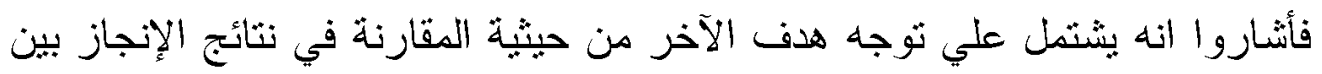
شخصين أو المنافسة بينهما في الإنجاز، لتكون التوجهات السداسية لأهداف الإنجاز 
مكونة من (إقدام-المهمة، إحجام-المهمة، إقدام-الآخر، إحجام-الآخر، إقدام-الذات، إحجام -الذات).

\section{التوجهات الثمانية لأهداف الإنجاز :}

بlliot بالنسبة لتوجهات الثمانبة لأهداف الإنجاز (التصنيف الثماني) فقد قام et al.(2015) بدر اسة جديدة عن نوجهات أهداف الإنجاز وبها وضح ان التوجهات

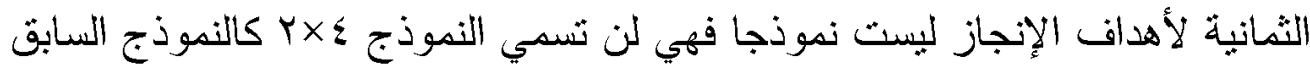
السداسي المسمى النموذج بx بل ثم التأكيد على ان التوجهات الثمانية نتجت من خلال معالجة النموذج السداسي س×r لتوجهات أهداث الإنجاز بسبب التوسع في مجموعة فرعية منه، وهي مجموعة الأهداف الذاثية فقط، وهي تعثمد علي المسار الفردي كمعيار للتقييم ويكون هذا المسار داخليًا للفرد اما يتمركز حول الماضي (أهداف الذات المبنبة علي الماضي) و هي الأهداف التي ثم ذكرها في النموذج السداسي (YXY) لتوجهات أهداف الإنجاز، أو يتمركز حول المستقبل (أهداف الذات

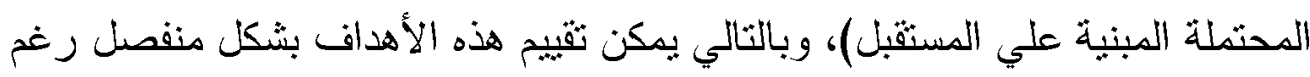
إدراجهما تحث فئة واحدة وهي فئة الأهداف الذاتية إلى الأهداف الذاتية المسندة إلى بلى لهاني الماضي والأهداف الذاتية المسندة إلى المستقبل، ومعيار تكافؤ ثثائي لكنًا منهما (إقدامًا وإحجامًا)؛ ليتم اقتراح أهداف ذات إقدام المستقبل Potential-approach

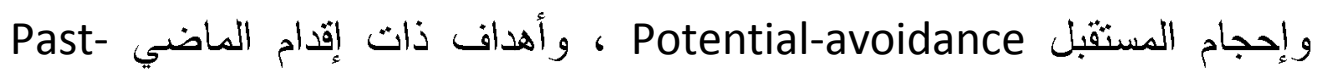
approach و وإحجام الماضي Past-avoidance ، وتعرّت الأهداث الذاتية بأنها الأهداف التي تعتمد علي المسار الفردي كمعيار للتقييم ويكون هذا المسار الداخلي اما قائمًا علي الماضي أو قائمًا علي المستقبل (Elliot et al., 2015). و اشتار ايضَأ(2015) بlliot et al. بأن ما ثم طرحه في النموذج السداسي من ابعاد نوجهات أهداف الإنجاز باقية كما هي في الثصنيف الثماني لنوجهات

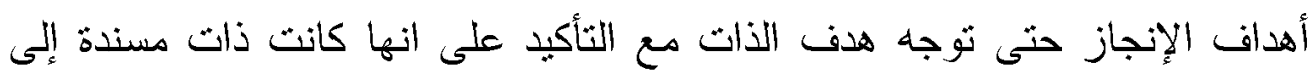
الماضي، وبعد المعالجة تم إدراج الذات المسندة إلى المستقبل لتتضح ان هذه 
المعالجة خصت ثوجه هدف (الذات) فقط في النموذج السداسي (Y×r) لتوجهات أهداف الإنجاز لتنكون التوجهات الثمانبة لأهداف الإنجاز من (إقدام-المهمة، إحجام-

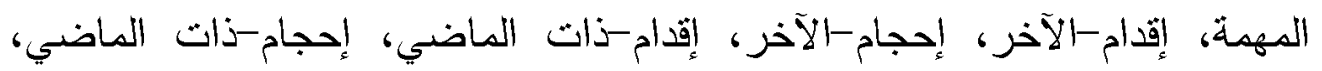
إقدام-ذات المستقبل، إحجام -ذات المستقبل).

\section{معايير تقيم التوجهات الثمانية لأهداف الإجاز:}

انشار (Elliot et al. أن معايير ثقييم توجهات أهداف الإنجاز نشمل كنًا من

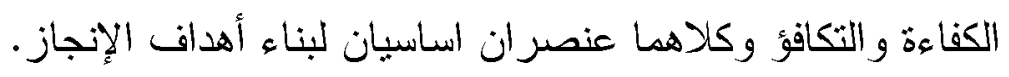
أ. معيار الكفاءة: بيّن (2015) .أن الكفاءة طريقة أساسية يمكن من

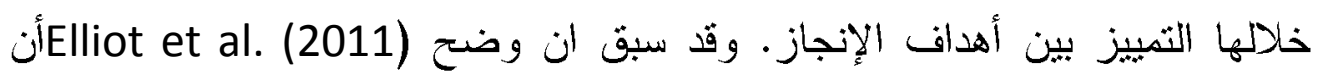

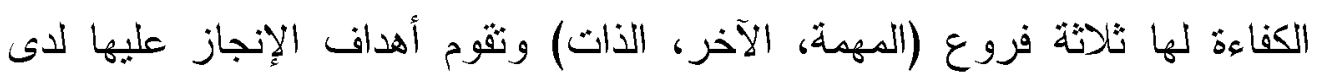
الأفر اد ونم ثوضيحها كالآتي:

- الأهداف القائمة على المهمة: هي ثنتخدم المنطلبات المطلقة للمهمة مثل الحصول على إجابة صحيحة أو فهم فكرة معينة.

- الأهداف القائمة على الآخر: هي تشتخدم الاشخاص كمرجع ثقييم، من حيث

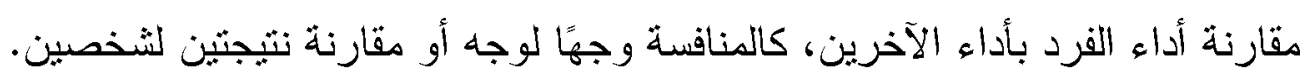
- الأهداف القائمة على الذات: هي تستخدم المسار الثخصي للفرد كمرجع ثقييم،

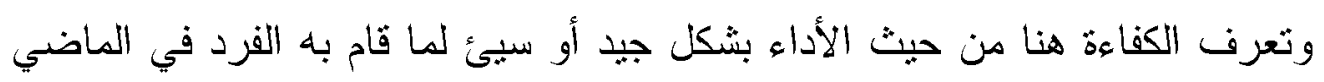
أو لديه القدرة على القيام به في المسنقبل(Elliot et al., 2011).

Y. معيار التكافؤ: بين (2011) . Elliot et al. بأنه ينقسم إلى فرعين وهما إما بالإقدام: ويكون بالنهج على الإيجابية في المهام، أو الإحجام: ويكون بتجنب السلبية في المهام. 
ابعاد التوجهات الثمانية لأهداف الإنجاز:

وعرّت (2011) . Elliot et al كنًأُ من نوجهات:

1. أهداف الإقدام القائمة علي المهمة: هي تستخدم المنطلبات المطلقة للمهية كمعيار تقييم للأداء، و الكفاءة هنا تكون بمحاولة القيام بالمهمة بشكل جيد.

ץ. أهداف الإحجام القائمة علي المهمة: هي تستخدم المنطلبات المطلقة للمهمة كمعيار تقييم للأداء، و الكفاءة هنا تكون بمحاولة تجنب القيام بالمهمة بنثكل ضعيف. r. أهداف الإقدام القائمة علي الاخر: هي تستخدم الاشخاص كمعيار ثقييم للأداء؛ و الكفاءة هنا تكون بمحاولة الاداء بشكل افضل من الآخرين.

ــ أهداف الإحجام القائمةعلي الاخر: هي تستخدم الاشخاص كمعيار ثقييم للذاءء، والكفاءة هنا تكون بمحاولة تجنب الاداء بشكل اسوء دن الآخرين (Elliot et al.,

وعرّت Eنlliot et al. ونًأ من نوجهات:

هـ أهداف الأات القائمةعلي إقدام الماضي:هي تستخدم المسار الثخصي كمعيار ثقييم للأداء ، و الكفاءة هنا تكون بمحاولة الاداء افضل من ذب قبل.

צ. أهداف الأات القائمة علي إحجام الماضي:هي تستخدم المسار الثخصي كمعيار تقييم للأداء، و الكقاءة هنا تكون بمحاولة تجنب الاداء ان بكون اسوء منذبي قبل.

V. أهداف الذات القائمةعلي إقدام المستقبل:هي تستخدم المسار الشخصي كمعبار تقييم للأداء، والكفاءة هنا تكون بمحاولة الارنقاء بمستوي الاداء المسنقبلي للفرد. 
^. أهداف الذات القائمة علي إحجام المستقبل:هي ثستخدم المسار الثخصي كمعيار ثقييم للأداء، والكفاءة هنا تكون بمحاولة تجنب الفنشل في الارتقاء بمسنوي الاداءالمستقبلي للفرد)(Elliot et al., 2015). و الثكل الثالي يوضح التوجهات الثمانية لأهداف الإنجاز .

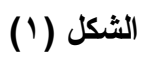

التوجهات الثمانية لأهداف الإجاز (إعداد: الباحثة)

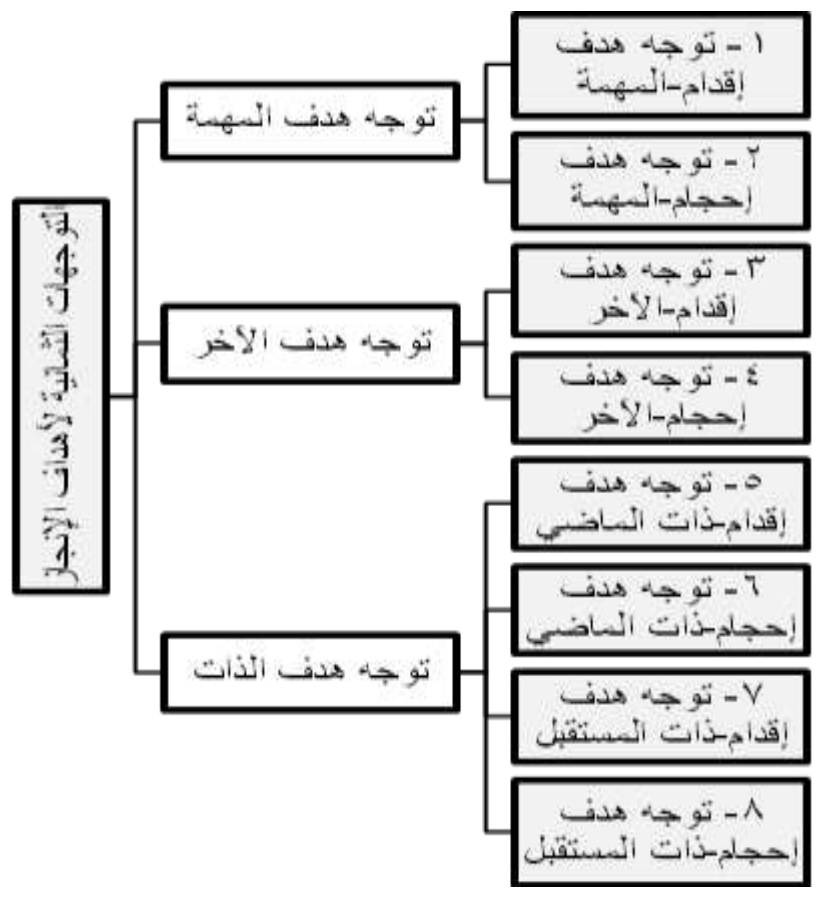

ثانيًا الدر اسـات السابقة:

تتاولت دراسة حجاج غانم(10 ب) التوجهات السداسية لأهداف الإنجاز، وهدفت إلى رصد فاعلية برنامج مقترح في إطار التوجهات السداسية لأهداف الإنجاز للمساهمة في زيادة مستوي الطموح، ونكونت العينة المشاركة من (YTV) ضابطة لمعالجة الفروض التجريبية وباقي عدد العينة لمعالجة الفروض الوصفية، 
و استخدم مقياس توجهات أهداف الإنجاز السداسبة والذي كان من إعداد الباحث،

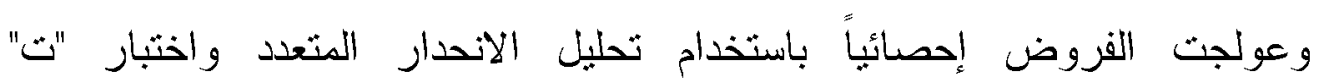
للمجموعتين المرتبطتين، ومن بين النتائج التي توصلت إليها الدراسة: أن التحصيل الاكاديمي يمكن التتبؤ به بواسطة التوجهات السداسية، وكان ثوجه إقدام المهية

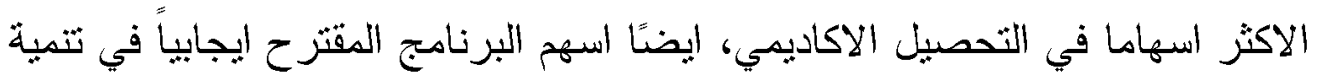
التوجهات السداسية جميعا، وبشكل منواليا سهم تتمويا في مسنوبي الطموح الاكاديمي.

كما تناولت دراسة(2015)Stan andOprea(الثوجهات الثناثية لأهداف الإنجاز، وهدفت إلى بحث ودراسة العلاقة بين ثوجهات أهداف الإنجاز الثلانثية

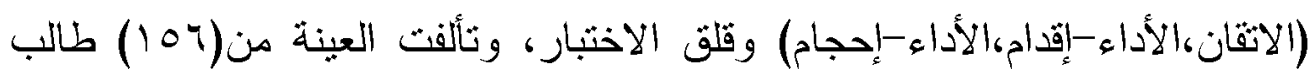

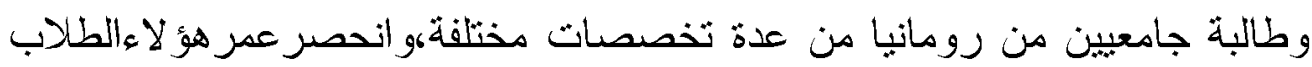

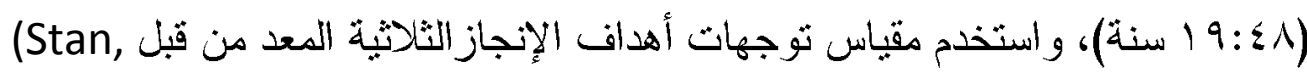
(2012و عدله الباحثان لبلائم طلاب العينة، واستخدم الإحصاء الوصفي ومعامل الارتباط الثنائي،وهن النتائج التي توصلت إليها الدراسة وجودعلاقة سليبة بين نوجهاء هدف الاثثان وقلق الاختبار، وبالعكس فقد تبين وجودعلاقة ايجابية بين نوجه هدف

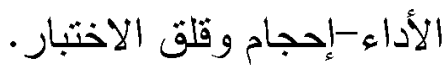

أما دراسة(2016).Sahin et al فقد نتاولت الثوجهات الرباعية، و هدفت إلى إلى معرفة تأثيرات النوع والعمرعلي نوجهات أهداف الإنجاز، و استخدمت مقياس

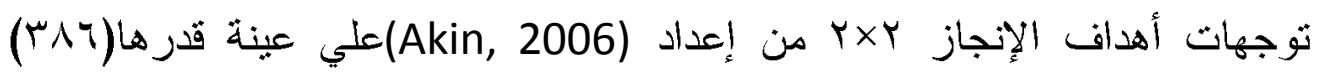

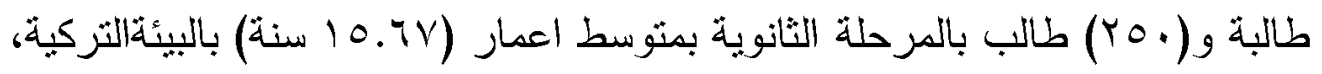
و استخدمت احصائيًا تحليل الثباين الثنائي،و اشتارت نتائجها إلى عدم وجود فروف بين طرفي النوع (الطلاب، الطالبات) في الاربعة نوجهات، ووجود فروق للعمر في التوجهات الإقدامية (الإتقان، الأداء) وكانت لصالح الطلاب الاصنغر سناً. 
بينما نتاولت در اسةE(2017) Elliott and Story النموذج الثائي للتوجهات

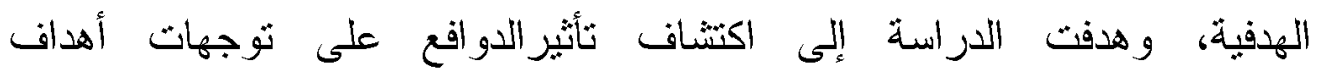

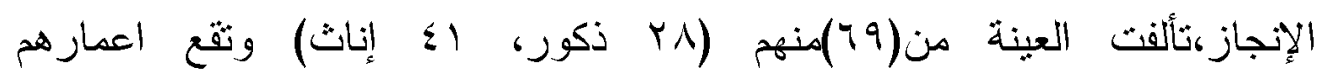

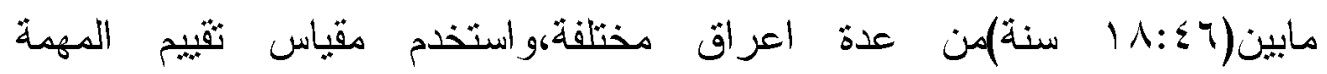
إعداد(Ryan,1982)،وقدمت نتائج منها نوجدعلاقة ارتباطية بين أهداف الإثقان و الدو افع الداخلية،ووجد علاقة ارتباطية بين أهداف الأداء و الدو افع الخارجية.

لكن دراسة (2017) نتاولت أحدث فرعين من التوجهات الثمانية لأهدات الإنجاز (توجه إقدام- ذات المستقبل،توجه إحجام-ذات المستقبل) فقط،وهدفت إلى التأكد من البنية العاملية والخصائص السيكومترية لمقياس توجه هدف إقدام-ذات المستقبل وتوجه هدف إحجام-ذات المستقبل الذبي كان من إعداد(Elliot et al., 2015)، ونألفت العينة من طلاب هاب جامعة هونج كونج بالصين،ويينت النتائج ان مقياس(Elliot et al., 2015)يتمتع بنسبة كبيرة من التباين المشترك وله ثوابت داخلية عاليةأي ينمتع بالصدق و الثبات.

أما دراسة(2018) Méndez-Giménez et al. قتد تتاولت التوجهات السداسية لأهداف الإنجاز، و هدفت إلى ثأثير الثوجهات الهدفية علي الدوافع الذاتية،

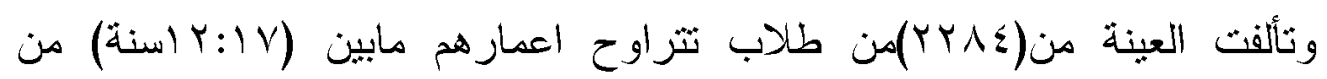

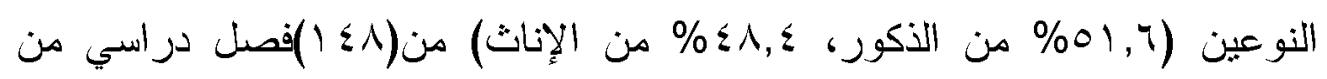
(Méndez-Giménez et al., المدارس بإسبانيا، واستخدمت مقياس من إعداد (2017، وعالجت الفروض إحصائياً من خلال تحليل الانحدار الخطي المتعدد،ومن النتائج التي توصلت إليها الدراسي ان توجه هدف إقدام-الذات وتوجه هدف إقدامالمهمة ينتبأن ايجابيًا بالدوافع الذاتية اما توجه هدف إقدام-الآخر وتوجه هدف إحجام -المههة نتبأن سلبًا بها. 
تثالثًا: تعقيب علي الار اسـات السابقة:

1- بالنسبة للعينة: ثناينت عينات الدراسات السابقة الثي تناولت منغير ثوجهات أهداف الإنجاز مابينالمراحل (الجامعية، الثانوية، الإعدادية، اعمار مختلفة)، فمن (Ning, الدراسات الثي تتاولت المرحلة الجامعية دراسة (حجاجغانم، 10)؛

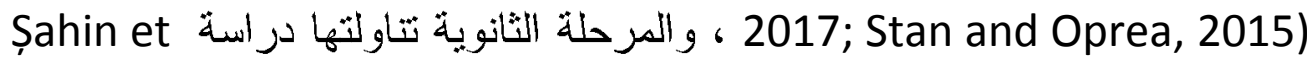

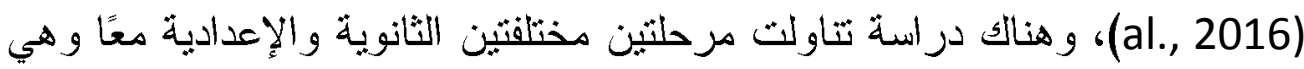
دراسة (Méndez-Giménez et al., 2018)، و هناك دراسة تتاولت عبنة من عدة اعمار مختلفة كدر اسة (Elliott and Story, 2017)،ويثضح من عرض كل ثلك الدراسات ان المرحلة الجامعية كان لها النصيب الأكبر من الدراسات، وسنخضع هذه الدراسة على طلاب المرحلة الإعدادية حيث انها مرحلة هامة كونها تحدد المسار التعليمي المستقبلي من نعليم عام وفني وتمريض وغيره من المسارات العلمية

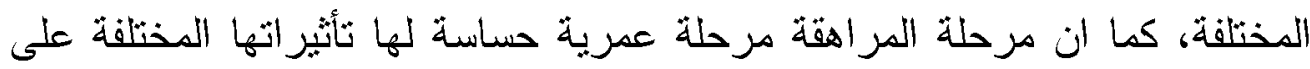

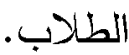

r- بالنسبة للأدواتيتضح من الدراسات السابقة ان معظم الدراسات اعتمدث على ملى ماتى

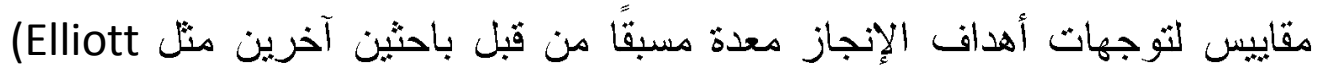
and Story, 2017; Méndez-Giménez et al., 2018; Neing, 2017;Șahin

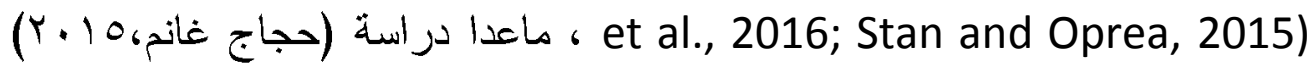
و التي فيها أعد الباحث المقياس بنفسه، وستخضع هذه الدراسة على تصميم مقياس بنفسها عن الثوجهات الثمانية لأهداف الإنجاز .

r- بالنسبة للنتائج: فقد بينت نتائج الدراسات ان ثوجهات أهداف الإتقان ارتبطت

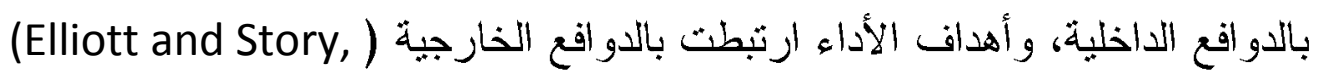
2017، وارتبط ثوجه هدث الأداء-إحجام وقلق الاختبار Stan and) (Opera,2015، وبينت نتائج الدراسات ايضًا ان ثوجهات أهداث الإنجاز تنبأت بكًا

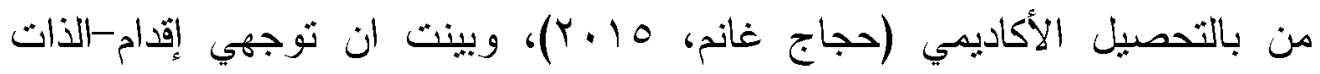


و إقدام-المهمة بيتبأن بالدو افع الذانبة(Méndez-Giménez et al., 2018)، وبينت النتائج تأثيرات النوع والعمر على الثوجهات الهدفية، فيبنت عدم وجود فروق فيها بين طرفي النوع، والتوجهات الإقدامية الإتقانية والأدائية لصالح الطلاب الأصغر سنًا (Sahin et al., 2016)، وستخضع هذه الدراسة لمعرفة مستويات التوجهات الثمانية لأهداف الإنجاز

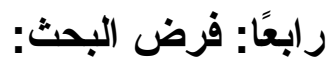

- تختلف متوسطات التوجهات الثمانية لأهداف الإنجاز اختلافا دالًا احصائيًاعن المتوسط الفرضي لدي طلاب المرحلةالاعدادية. إجر اعاث البحث: - أبح: منهج البحث:استخدم البحث المنهج الوصفي. مجتمع البحث:المجتمع الذي قصده البحث مجنمع طلاب المرحلة الإعدادية بصفوفها الثلاث (الاول، الثاني، الثالث) من مختلف ارجاء جمهورية مصر العربية في العام

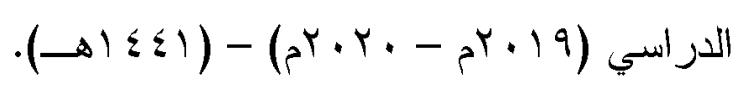

عينة البحث الاستطلاعية: ثم اختبار عينةعرضية، تكونت من (0؛ ) طالب وطالبة من طلاب المدارس المنتظمة من مدرسة البياضية للتعليم الأساسي ومدرسة

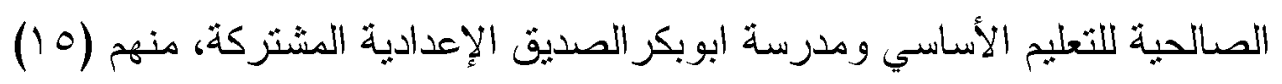

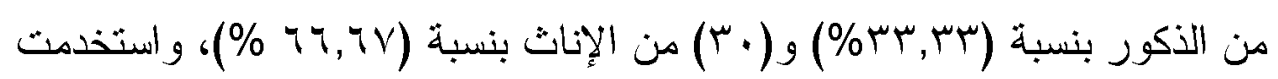
هذه العينة بغرض التأكد من صداحية المقباس المعد.

\section{عينة البحث}

الاساسية: ثم اختبارعينة عرضبة من مجتمع البحث الأصلي وذلك من خلال ناحبتين مختلفتين: من المدارس الحكومية المنتظمة والذين ثمثلو الثي ثثلاثة مدارس إعدادية

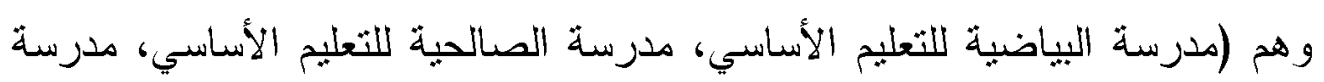


ابوبكر الصديق الإعدادية المشتركة) و أخذت استجاباتهم علي المقياس المعد في نسخة

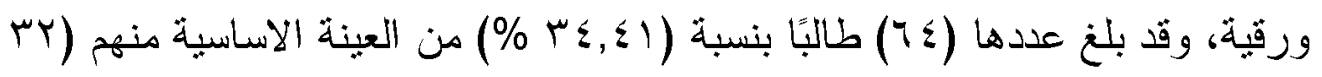
طالب ، بس طالبة)،ومن بعض طلاب المرحلة الإعدادية من مختلف انحاء جمهورية

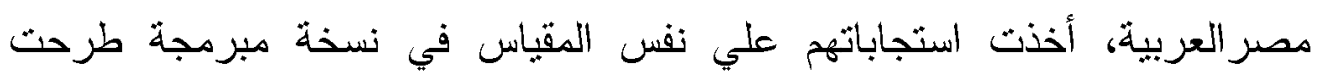
إلكترونيًا، وتم اللجوء لذلك بسبب جائحة فيروس كورونا (COVID-19) وما خلفته من إغلاق المدارس والحجر المنزلي للطلابهوقدبلغ عددالطلاب الذين قدموا

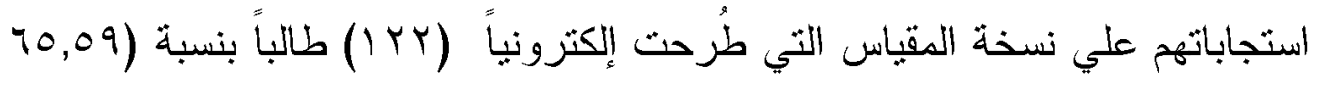
\%) من العينة الاساسية منهم (9 ط طالب ، س طالبة)، ليتألف عدد العينة الاساسية

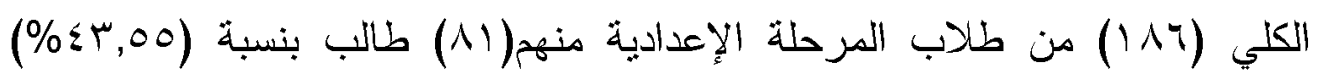

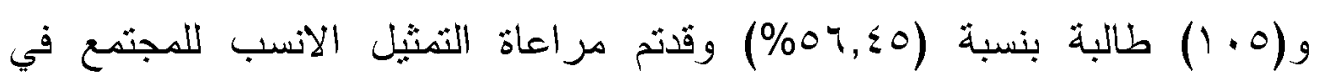
اختبار هذه العينة. أداة البحث الأساسية: مقياس التوجهات الثمانية لأهداف الإججاز (إعداد الباحثة): The measure of the eight orientations of achievement goals

الطريقة إعداد المقياس:قامت الباحثة بتحديد ابعاد نوجهات أهداف الإنجاز الثمانية استتادا إلى ما نطرق له(Elliot et al.,2011; استتادًا للأدب السابق الذي ثتاول منغير التوجهات الهدفية سابقًا، كما تم الاستتاد ايضًا إلى عدة مقاييس أعدها باحثين آخرين منهم (مقياس التوجهات السداسية لحجاج

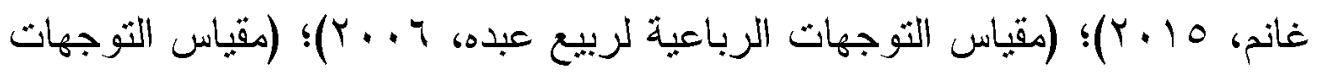

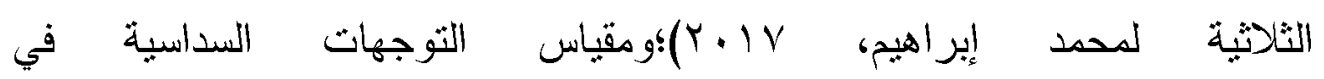
(Elliotetal.,2011)ومقياس (Elliot et al.,2015) لتوجهي (إقدام ذات الماضي، إحجام ذات الماضي).

وقد قامت الباحثة من خلال ماسبق بإعداد (ب) فقرة في مختلف ابعاد التوجهات الثمانية لأهداف الإنجاز وقام حجاج غانم (في هذا البحث) بإعداد (ع) فقرات فئن فيعهم 
في بُعد(توجه إحجام-ذات المستقبل)وهم: (احرص على ألا يتأخر مستواي يوما بعد

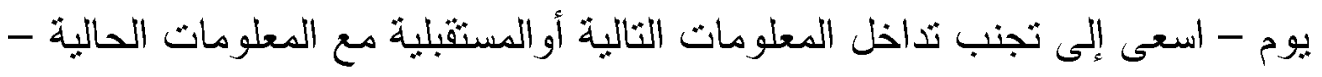

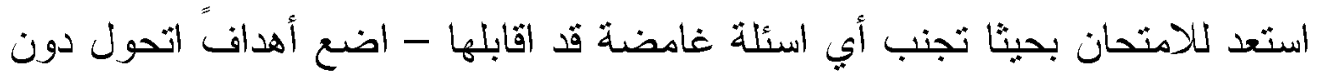

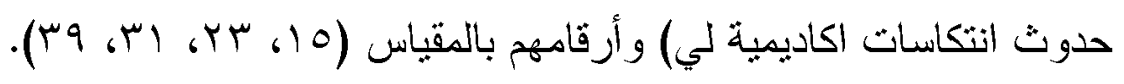

r- وصف المقياس:هذا المقياس لقياس درجة كل ثوجه من التوجهات الثمانية لأهداف الإنجاز ، وتكون في صورته النهائية من (qr) فقرة بموجب خمس فقرات لكل بعد من

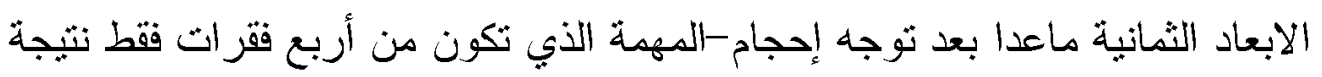
لحذف فقرة كان ثباتها حسب معادلة ألفاكرونباخ أضعف من ان ثبقي في المقياس، بونه

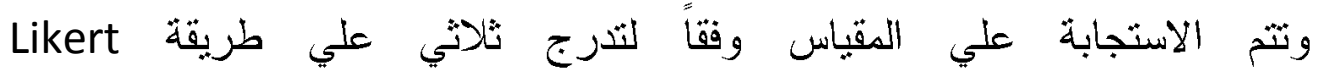
(غالًَا،أحيانًا،نادرًا) وتصحح جميع الفقرات بدرجات (س، ب، ( ) على التو الي وينم احتساب الدرجة للمفحوص من خلال جمع درجاته في كل بعد علي حدة من ابعاد توجهات أهداف الإنجاز. r- صدق مقياس التوجهات الثمانية لأهداف الإنجاز: أـ صدق الارتباط بمحك خارجي:استخدم مقياس التوجهات السداسية لأهداف الإتجاز إعداد(حجاج غانم، 10 ب ب) كمحك خارجي لقياس صدق المقياس المعد في البحث و هومقياس التوجهات الثمانية لأهداف الإنجاز، ولحساب الصدق استخدمت الباحثة

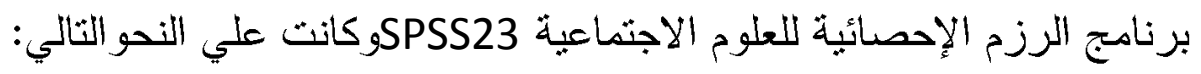

- ان معاملات الارثباط بين نوجهات الأهداف الإقدامية الثمانية(من المقياس المعد) وتوجهات الأهداف الإقدامية السداسية (من مقياس المحك الخارجي) كانت

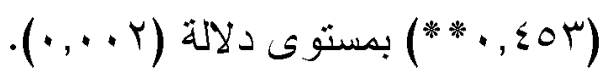

-ومعاملات الارثباط بين ثوجهات الأهداف الإحجامية الثمانية (من المقياس المعد) وتوجهات الأهداف الإحجامية السداسية(من مقياس المحك الخارجي) كانت الإنه

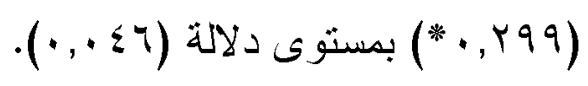


ومعاملات الأرتباط بين الدرجة الكلية للتوجهات الثمانبة (المقياس المعد) و الدرجة

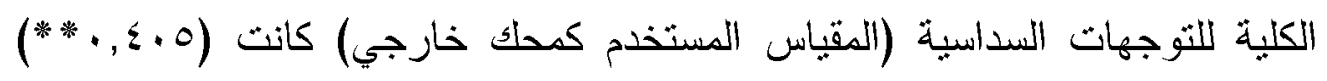

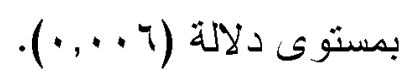

ويتضح من جميع معاملات الارتباط انها حققت ارتباطات دالة معأعند مستوي دلالة

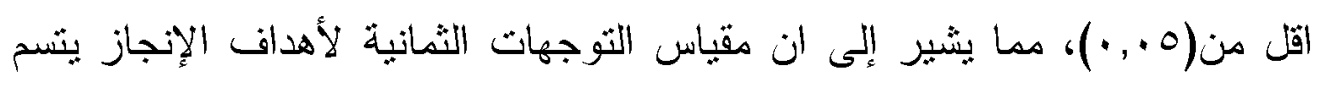

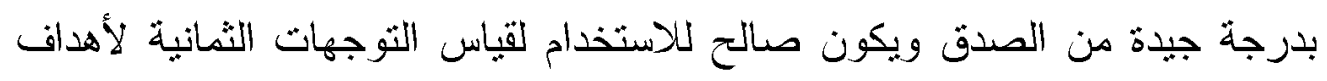

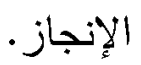

ب- صدق المجموعات المتضادة: قامت الباحثة بحساب مقارنة المنوسطات بين

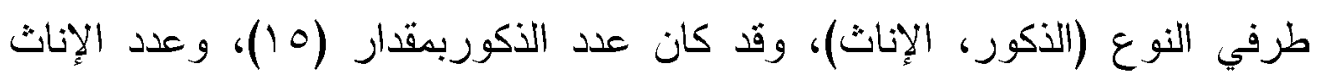

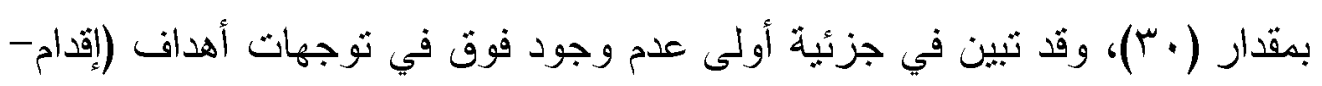

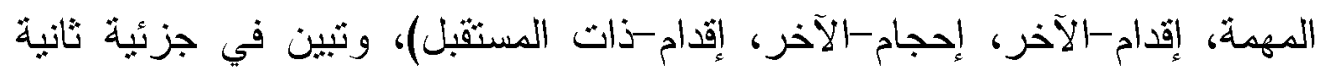

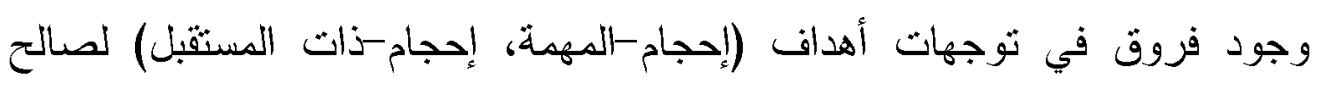

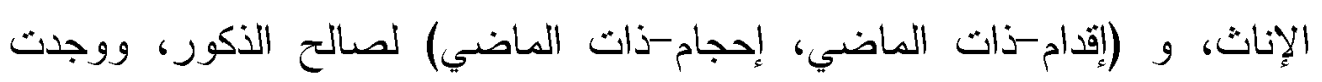

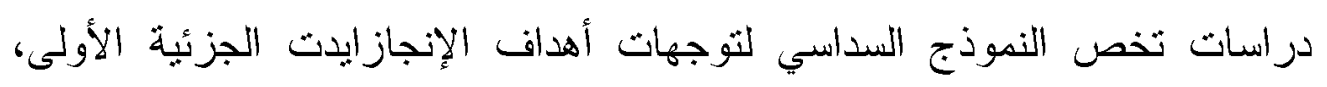

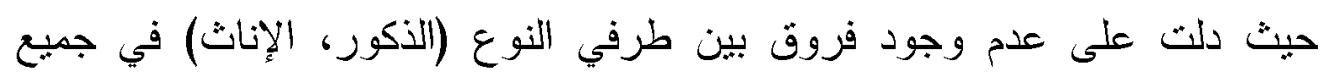

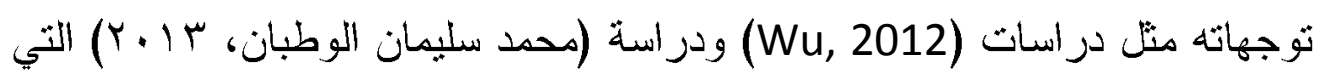

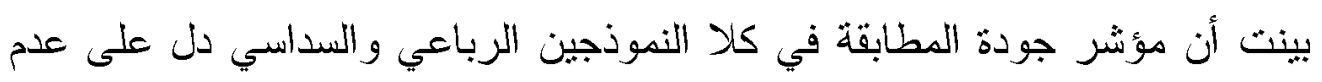

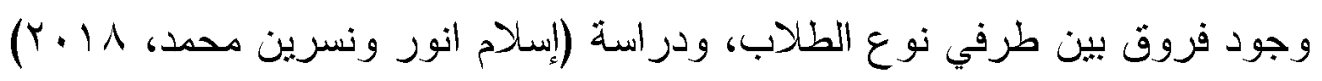

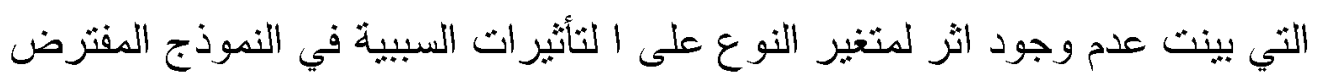

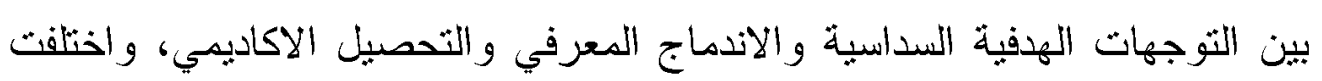

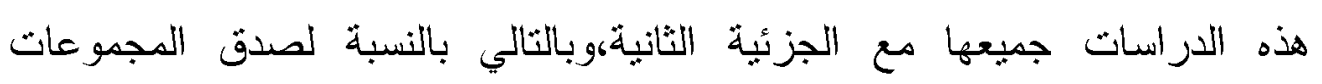

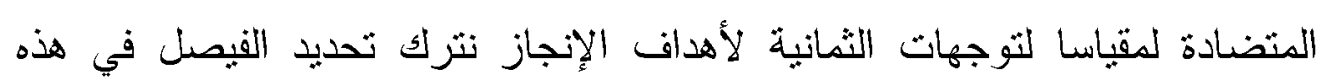
النقاط للباحثين الذين سوف ثأني ابحاثهم بعد بحثنا هذا. 
ج- صدق الآساق الإخلي: لحساب صدق مقياس التوجهات الثمانية لأهداف الإنجاز

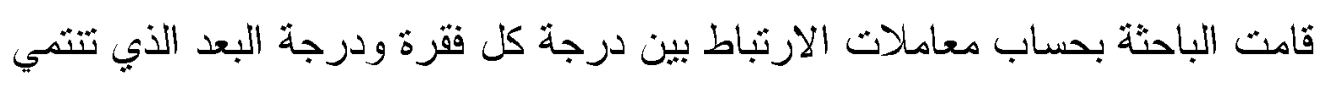

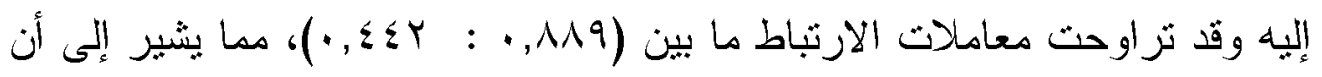
جميع فقرات المقياس حققت ارتباطات دالة مع الدرجة الكلية للبعد الذبي تنتمي إليه

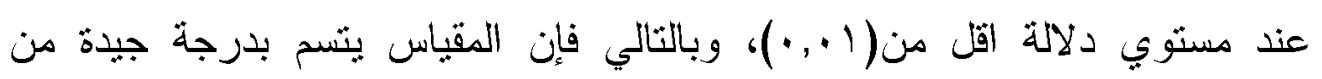
الاتساق الداخلي ويكون صالح لثقدير الثماني توجهات.

د- الصدق الظاهري لمقياس التوجهات الثمانية لأهداف الإنجاز: من خل المراجعة الادب السابق والمراجع الدذكورة في هذا البحث وتحليل مفهوم نوجهات أهداف

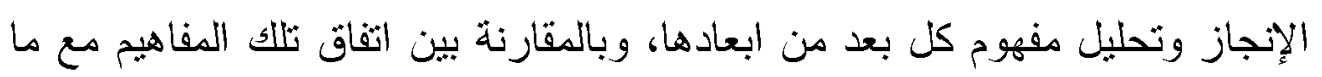

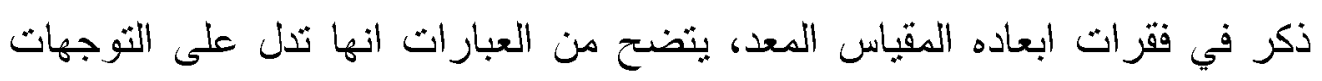

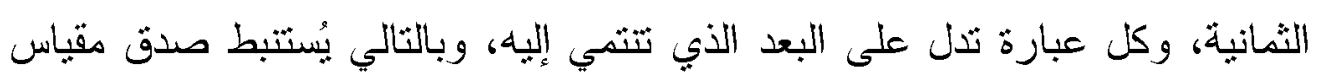
النوجهات الثمانية لأهدات الإنجاز.

ءـ ثبات مقياس التوجهات الثمانية لأهداف الإنجاز:

أـ ثبات المقياس باستخدام طريقة ألفاكرونباخ: ثم تقدير ثبات المقباس من خلال حساب معاملات الثبات لأبعاد وفقرات مقياس التوجهات الثمانية لأهداف الإنجاز

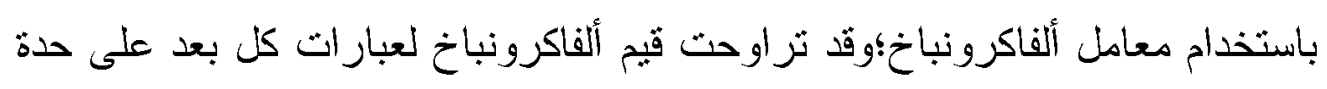

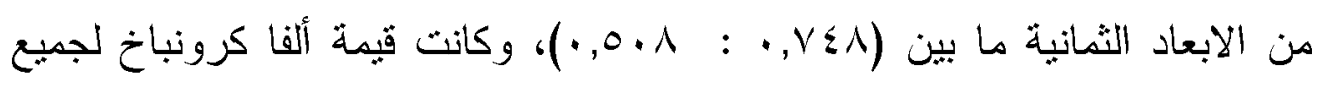

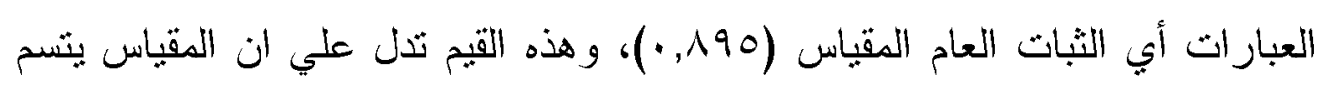
بدرجة ثبات عالية. 
ب- طريقة التجزئة النصفية : قامت الباحثة بحساب الثبات لمقباس الثوجهات الثمانية لأهداف الإنجاز بطريقة التجزئة النصفية واستخدمت معادلة جنمان Guttman

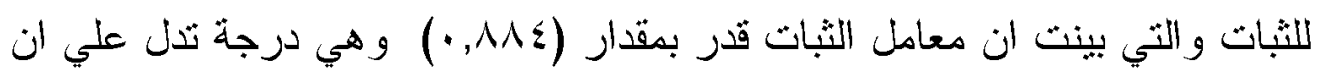
المقياس بتسم بدرجة ثبات مرتفعة.

ومماسبق يثضح من دلالات الصدق والثبات التي ثمت ان مقياس الثوجهات الثمانية لأهداف الإتجاز ينسم بدرجة جيدة من الصدق والثبات للتوصل إلى نتائج معززة بهم في هذا البحث.

هـ الأساليب الإحصائية: ثم استخدام برنامج الحزم الإحصائية للعلوم الاجنماعية SPSS23 بشكل رئيسي في تفريغ الييانات ومعالجتها إحصائياً، وتم استخدام معامل ارنباط بيرسون للتحقق من صدق الارثباط بمحك للمقياس المعد، ومعادلة جنمان للتحقق من ثبات التجزئة النصفية، معادلة ألفاكرونباخ لحساب الثبات، ومقارنة One المنوسطات لحساب صدق المجموعات المنضادة، واختبار "ت" للعينة الو احدة Sample T-Test

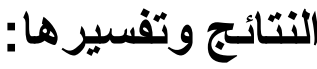

نتيجة الفرض والذي بنص على: تختلف متوسطات التوجهات الثمانبة لأهداف الإنجاز اختلافًا دالًا إحصائيًا عن المثتسط الفرضي لدى طلاب المرحلة الإعدادية.

للتحقق من صحة هذا الفرض ثم معالجته الإحصائية من خلال استخدام اختبار "ت" للعينة الواحدة، One Sample T Test ، والجدول التالي يوضح نتيجة هذا

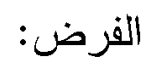




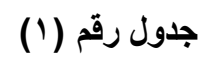

نتيجة اختبار "ت" للعينة الواحدة للتعرف على مستويات افر اد عينة البحث في الابعاد الثمانية لتوجهات أهداف الإنجاز ملنوات

\begin{tabular}{|c|c|c|c|c|c|c|c|}
\hline حجم التأثير d & "دلادة & الحرية & "تتبار & الفرضي & المعياري & التجريبي & البيان \\
\hline سד ؛, ا (كبير) & $\ldots \cdots$ & 110 & $19,97$. & 1. & $1, \wedge \leq \varepsilon$ & ir,v. & توجه إقام-المهمة \\
\hline Vדז, 1 (كبير) & $\because \cdots$ & 110 & $i v, r \vee q$ & $\wedge$ & $1,0 \wedge \vee$ & $1 \cdot, \cdot 1$ & توجه إحجام_المهمة \\
\hline r rr, (كبير) & $\because \cdots$ & 110 & $r Y, I Y V$ & 1. & $1, \times 47$ & $M r, A r$ & توجه إقدام-الآخر \\
\hline (كبير), (كVI) & 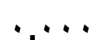 & 110 & $1 ., 011$ & 1. & $r, 19$ & 11,00 & توجه إحجام-الآخر \\
\hline (كبير) & $\because \cdots$ & 110 & $r r, v \otimes 0$ & 1. & $1, \wedge \div \vee$ & $1 r, r_{0}$ & توجه إقدام_ذات الماضي \\
\hline r & $\because \cdots$ & 110 & $r \cdot, V Y 0$ & 1. & $r, 91$ & $I r, \cdot v$ & توجه إحجامذات الماضي \\
\hline ץדף, • (كبير) & $\because \cdots$ & 110 & o & 1. & $r, . \Delta v$ & 11,91 & توجه إقدام_ذات المستقبل \\
\hline 1,110 (كبير) & $\because \cdots$ & 110 & $10, Y 11$ & 1. & $1,9 \times \wedge$ & 14,10 & توجه إحجام-ذات المستقبل \\
\hline
\end{tabular}

النتيجة نقبل الفرض حيث بتضح من الجدول (1) صحة الفرض (تختلف منوسطات

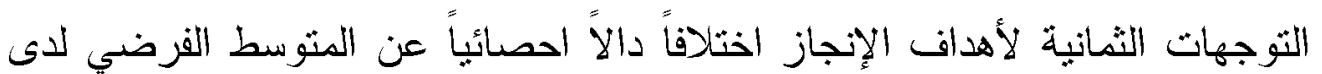
طلاب المرحلة الإعدادية)، ويتضح من الجدول(1) (1):

- ان الطلاب عينة البحث ينسمون بمستويات مرتفعة من التوجهات الثمانية لأهداف الإنجاز، وهذا ما يتضح من قيم الدلالة لاختبار "ت" حيث ان جمبعها كانت بمستوي دلالة (. ....)، وجاءت النتائج جميعها بإحجام ثأثثر (كييرة) وجميعها مقبولة.

- ميتضح ايضًا من دلالة قيم (ت) أن مثوسطات الثوجهات الثمانية لأهداف الإنجاز جميعها كانت اعلي من المتوسط الفرضي لدى الطلاب وهذا ما يبين صحة قبول الفرض الاول في هذالبحث وهو (تختلف منوسطات اللوجهات الثمانية لأهداف الإنجاز اختلاف أدالاً إحصائياًعن المتوسط الفرضي لدى طلاب المرحلة الإعدادية).

$* d=\frac{t}{\sqrt{\mathbb{N}}}, \quad$ small $=0.2$ medium $=0.5$ large $=0.8$

المتوسط الفرضي= النقطة المحايدة × عدد عبار ات البعد الواحد.

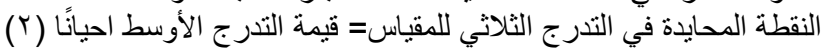


ونجد ان هذه النتيجة طبيعية حيث ان الطلاب بتسمون بمستويات مرتفعة

ومقبولة من التوجهات الثمانية لأهداف الإنجاز؛ فهدف الطلاب الاول البديهي من

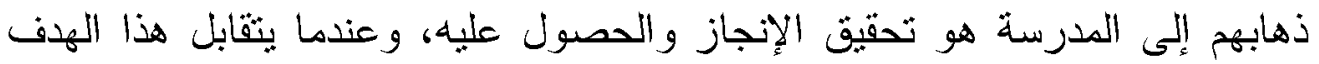
مع الفروق الفردية والثي ايضًا تكون بديهية لايهم، فإن الطلاب بختلفون في الطرق التي بيلكونها في تحقيق هدفه الاول وهو تحقيق الإنجاز المدرسي، ويظهر ان لكل طالب وجه خاصنة يستخدمها يتوسم من خلالها تحقيق هدف الإنجاز، وبالتالي ثرتفع مستويات التوجهات الهدفية على اختلاف انواعها.

ونعزو سبب ارتفاع مستويات التوجهات الثمانبة لأهداف الإنجاز عند

الطلاب برنبط بما ذكره (Was, 2006) أن نوجه الهدف يكون جانب متعدد الاوجه (Was and Beziat, بوضح كيف يقترب الطلاب من الإنجاز المدرسي؛ واضاف (2015ان التوجهات الهدفية نتعلق برصد المعرفة بطرق منتوعة؛ واثشار (ربيع

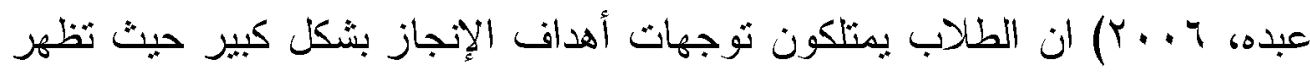
لدي الطلاب الذين يريدون تحقيق الإنجاز من اجل الحصول على درجات أو نيل إعجاب الآخرين أوالثتعور بقيمة الذات أو من اجل تجنب وتفادي الفتشل والحرج ونقص القدرة.

ومن نتائج الدراسات السابقة التي تقاربت مع نتيجة هذا الفرض دراسة رفعه

حسن ورافع الزغول (10 ب ( التي دلت نثائجها ان المنوسطات الحسايية للتوجهات الثناثثة لأهداف الإنجاز بينت ان توجهي هدف التمكن وإحجام الأداء كانوا ذو مستوى مرتفع وتوجه إقدام الأداء ضدن المستوي المتوسط لدى عينة البحث، ودراسة (MaehrandZusho, 2009) التي ثوصلت ان معظم الطلاب كانوا يمتلكون توجهات أهداف (الاتقان-إقدام ، الاثقان -إحجام، الأداء-إقدام، الأداء-إحجام) بشكل مقبول لاى عينة البحث. 
ومن نتائج الدر اسات السابقة التي استخدمت اختبار One Sample T-Test وتو افقت وتقاربت مع نتيجة هذا الفرض دراسة (صادق كاظم وزينب خضر،

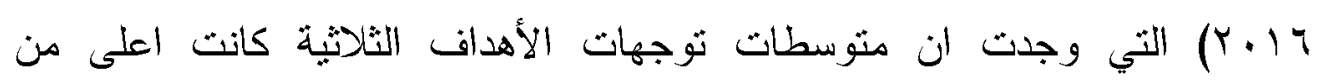
المتوسط الفرضي وكانت ثوجهات أهداف (الثمكن، الأداء-إقدام) ذو دلالة إحصائية

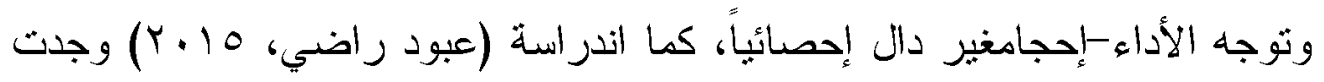
ان الطلاب يمتلكون بوجه عام ومقبول ثوجهات أهداف الإنجاز الرباعبة (الإثقان إقدام، الإتقان -إحجام، الأداء-إقدام، الأداء-إحجام).

بينما هناك دراسات اتفقت في جزئية واختلفت في جزئية اخرى مع نتيجة

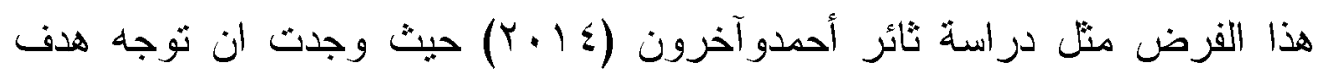

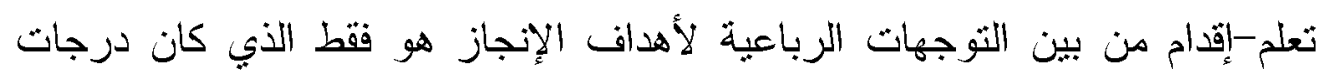
متوسط العينة اعلى من المثوسط الفرضي للمقياس المستخدم، ودراسة إسلام انور ونسرين محد (1/. Y) التي دلت نتائجها ان توجهات أهداف الآخر (الإقدام

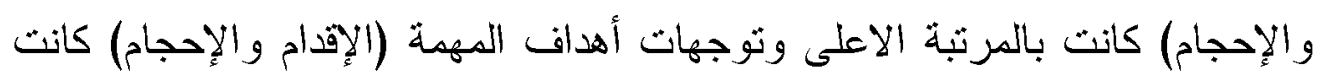
بالمرتبة المتوسطة بينما كانت توجهات أهداف الذات الاقل هن بين التوجهات الهدفية لأفر اد العينة.

توصيات البحث: في ضوء ما قدمه البحث من نتائج يمكن ثقديم نوصيات لكًا من أولباء الامور و القائمين على العملية التربوية وو اضعي المناهج الدراسبة بما بلي: - تشجيع الطلاب علي تقبل انفسهم، وفي ذات الوقت لفت نظرهم إلى إمكانية تحسين مستو اهم الدراسي للأفضل مهها كان مستوي أداءهم الحالي.

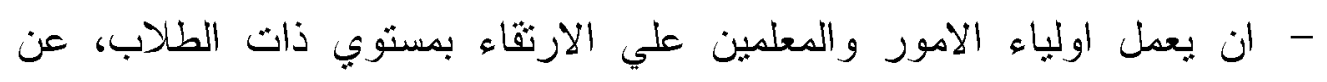

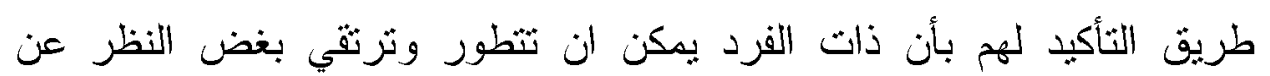
مستو اها الآن. 
- بجب ان نشجع الطلاب ذوي نوجه إحجام-الآخر ان بنبنوا إقدام الذات، ونؤكد لهم ان قيمثهم في ذات انفسهم وليس في ما يراه الآخرون عنهم، والتأكيد لهم لهم علي وجوبية طرد النظرة السليية التي قد يروها في آراء اقرانهم عنهم، و استبدالها بالقوة الداخلية الذانية للقرد.

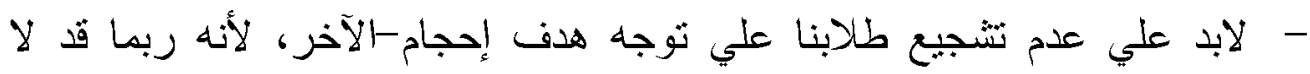
يثجع علي جو صدي تعليمي مناسب للطلاب خاصة في مرحلة المر اهقة.

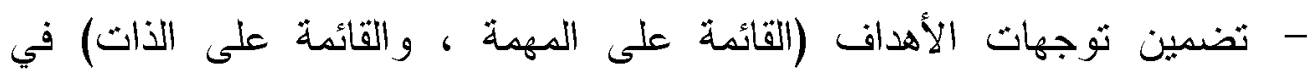
المناهج التعليمبة، كتضمين درس بالمناهج التعليمية بلفت نظر الطلاب حول ولهابه كيفية تبني هذه التوجهات. بحوث مقترحة:

1- تصميم برنامج مقترح لتمية ثوجهات (إقدام-المهمة، إقدام-ذات المستقبل) و أثره على دافعية الإنجاز لدى طلاب المرحلة الإعدادية.

ץ- فاعلية برنامج مقترح قائم على التوجهات الهذفية الذاتية لتحسين المزاج لدى المتنمر عليهم للي طلاب المرحلة الإعدادية.

ب- ثأثير التوجهات الثمانبة لأهداف الإنجاز على أساليب حل المشكلات لدى عينة المر اهقين. - مان. 
التوجهات الثمانية لأهداف الإنجاز لاى طلاب المرحلة الإعدادية

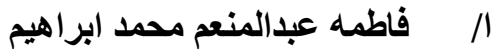

$$
\text { المقياس }
$$

مقياس التوجهات الثمانيةلأهداف الإججاز، إعداد: الباحثة

\begin{tabular}{|c|c|c|c|c|}
\hline نادرًا & أحياتًا & غالبًا & العبارة - از & 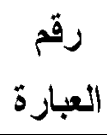 \\
\hline & & & الدرجة عذدي تعبر عن مدى فهي للمادة الدراسية. & 1 \\
\hline & & & أسعى إلى ان يكون مستواي الدراسي افضل من ذي قبل. & r \\
\hline & & & أحرص على أداء مهامي الدراسية بشكل لائق أمام زملاهي. & $r$ \\
\hline & & & لاستخداد أقصى إمكانياتي وطاقاتي وقدراتي في الاستذكار ، & $\varepsilon$ \\
\hline & & & تر أحرص على أداء واجباتي المدرسية اولًا بأول، خوفًا من & • \\
\hline & & & علدم تكرار نفس الدرجة علي درجة منذفضة، أسعى لبذل جها إضافي & 7 \\
\hline & & & لي أمرص زملهى أداء واجباتي الددرسية، تجنبًا لعدم إحراج المعلم & $v$ \\
\hline & & & أخثلى ان أجيب علي سؤال محتمل من المعلم، بقلر أقل مما & $\wedge$ \\
\hline & & & هدفي يكون إثباع شغف العلم والتعلم من ذهابي إلى المدرسة. & 9 \\
\hline & & & عندما أحقق هدفًا، أضع هدفًا آخر اكبر من سابقه أسعى & $1 \cdot$ \\
\hline & & & أريد ان أنجح في الاختبارات حنى أسعد شخص يهتم لنجاحي. & 11 \\
\hline & & & 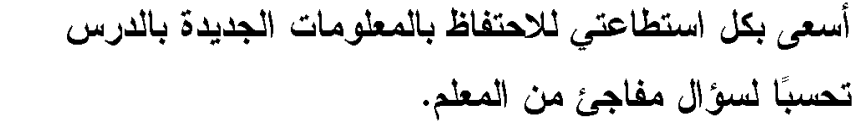 & ir \\
\hline & & & هأدائي الدراسي الجنب ان يكون أدائي الاراسي الحالي اسوء من & $1 T$ \\
\hline & & & عند حصولي علي درجة ضعيفة، لا أعلنها امام زملاتي. & $1 \varepsilon$ \\
\hline & & & أحرص على ألا يتأخر مستواي يومًا بعد يوم. & 10 \\
\hline & & & هدفي اكتساب مطلومة جديدة من كل درس جديد. & 14 \\
\hline
\end{tabular}

\begin{tabular}{|c|c|}
\hline أغسطس • Y. P & $-Y 01=$ \\
\hline
\end{tabular}


التوجهات الثمانية لأهداف الإنجاز لاى طلاب المرحلة الإعدادية

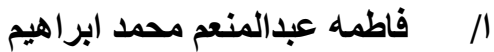

\begin{tabular}{|c|c|c|c|c|}
\hline 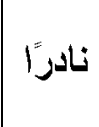 & أحياتًا & غالبًا & 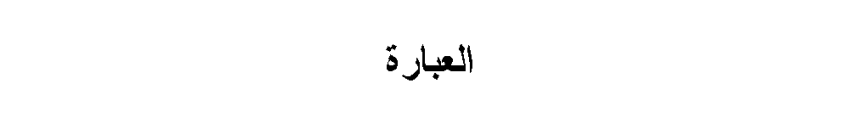 & العبارة - مقم \\
\hline & & & وقت مضى. على تطوير ذاتي في الدراسة لكي اكون افضل من أي & iv \\
\hline & & & أسعى ان يكون مستواي الاراسي افضل من مستوى الآخرين. & 11 \\
\hline & & & بأبكبر قثر مدكن. أبلاري جهي في تحضير درسي القادم، حتي استوعبه & 19 \\
\hline & & & أتجب الأجل الاجابة عن الاسئلة الصعبة الى ما بعد السهلة، حتي & $r$. \\
\hline & & & أعمل جاهدًا على التقليل من اخطائي الدراسية السابقة. & r \\
\hline & & & أنجنب الزسوب في الامتحانات، حتي لا يحزن شخص يهتم & rt \\
\hline & & & أسعى إلمى تجنب تداخل المعلومات التالية أو المستقبلية ميع & rr \\
\hline & & & أحرص عنى الداء واجباتي المدرسية كنها حتي التي لا يسأل & Y\& \\
\hline & & & أحثر من السابق. على استذار دروسي عدة مرات، حتي يزيد فهي نها & ro \\
\hline & & & أثشعر بسعادة عند مدح المعلم لي أمام زملاتي. & ry \\
\hline & & & أضع هدفا بعيد المدي، استخدم كل إمكانياتي وطاثاتي لإحرازه. & $r v$ \\
\hline & & & أحرص على الإصغاء لمعم المادة، حتى أتجنب ضياع & rA \\
\hline & & & 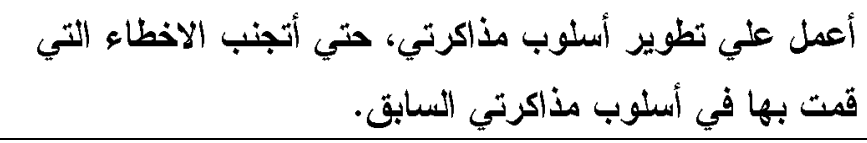 & rq \\
\hline & & & أذاكر فقط ما سوف يناقش بالصف، خوفاً من ظهوري بمستوي & $\mu$. \\
\hline & & & أستعد للامتحان بحيث أتجنب أي اسئلة غامضة قد أقابلها. & $r_{1}$ \\
\hline & & & عند تكليفي بههة أحرص علي أدائها بثكل جيد. & rr \\
\hline
\end{tabular}


التوجهات الثمانية لأهداف الإنجاز لاى طلاب المرحلة الإعدادية

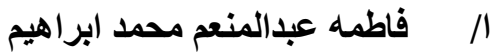

\begin{tabular}{|c|c|c|c|c|}
\hline نادرًا & أحبانًا & غالبًا & 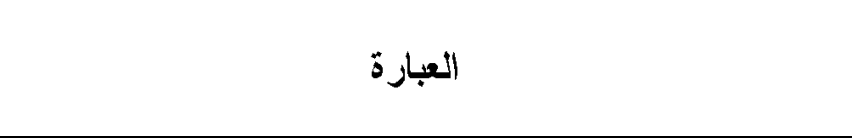 & 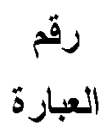 \\
\hline & & & أحرص على تطوير أسلوب مذاكرتي، حتي يتقلم مستواي & $\mu \mu$ \\
\hline & & & 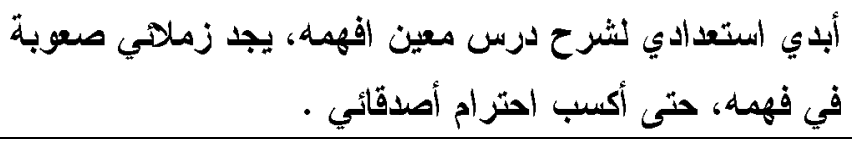 & $\Gamma \xi$ \\
\hline & & & أستعد بقر الإمكان لامتحانات آخر العام منذ بداية العام & ه \\
\hline & & & أتجنب الاهمال في مذاكرة الدروس خثية عدم فهها جيدًا. & $r$ \\
\hline & & & درس جرص على تطوير مهار اتي الثخصية، للتظب علي صعوبة & $\mu v$ \\
\hline & & & أتجنب الإجابة عن اسئلة معلم الصف، خوفاً من ان تكون & $\mu \wedge$ \\
\hline & & & أضع أهدافًا تحول دون حدوث انتكاسات أكاديمية لي. & ra \\
\hline
\end{tabular}

جدول يبين فقر ات كل بعد من ابعاد مقياس التوجهات الثمانية لأهداف الإنجاز

\begin{tabular}{|c|c|c|c|c|c|c|c|c|}
\hline أحجات & ألقات ام- & الماتــ & ألماضـي & إلآخام- & إلآثر & المهمجة & إلمهمة & البعد \\
\hline$\wedge$ & $\varepsilon$ & 7 & $r$ & V & r & \multirow{5}{*}{$\begin{array}{c}0 \\
r . \\
r \wedge \\
r u\end{array}$} & 1 & \multirow{5}{*}{ العبار ات } \\
\hline 10 & IT & 14 & 1. & $1 \varepsilon$ & 11 & & 9 & \\
\hline rT & 19 & $\begin{array}{l}11 \\
\text { r }\end{array}$ & IV & r & 11 & & 17 & \\
\hline I & TV & עי & Yo & $r$. & Y & & $r \varepsilon$ & \\
\hline rq & ro & & זץ & ץへ & $\Gamma \varepsilon$ & & Tr & \\
\hline
\end{tabular}

جدول يبين قيمة درجات تدرج مقياس التوجهات الثمانية لأهداف الإنجاز

\begin{tabular}{|c|c|c|c|}
\hline نادرًا & احيانًا & غالبًا & التدرج \\
\hline 1 & $r$ & $r$ & الدرجة \\
\hline
\end{tabular}




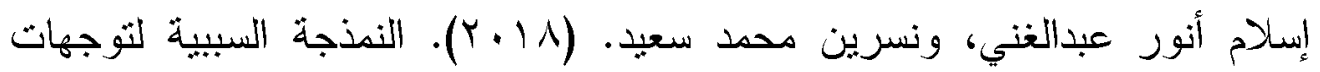

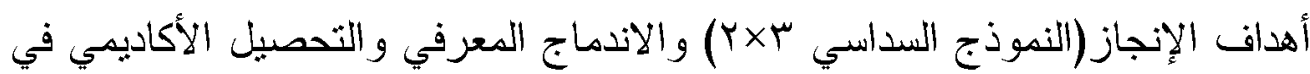

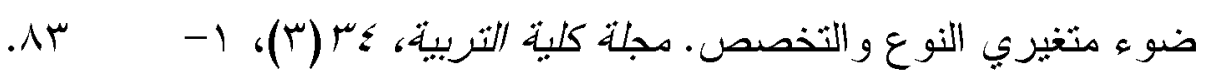
ثائر أحمد غباري، جلال كايد ضمرة، ويحبى حياتي نصار. (ع إب). علاقة التوجهات الهدفية بسلوك البحث عن التغذية الراجعة لدى عبنة من طلبة الجامعة

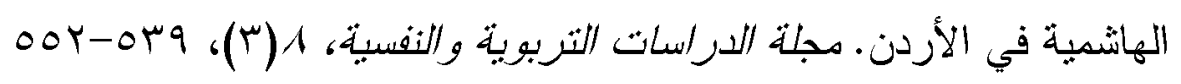

حجاج غانم أحمد. (10 (10). فاعلية برنامج مقترح لتنمية التوجهات السداسية لأهداف الإنجاز واثره علي مستوي الطموح الاكاديمي لابي طلاب كلية التربية

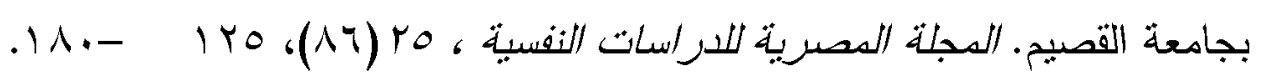

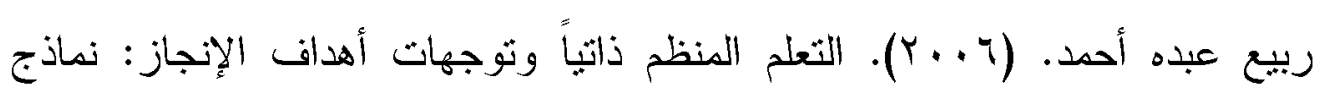
ودر اسات معاصرة. عالم الكتب.

رفعه حسن تايه ور افع الزغول. (10 ب r). العجز المتعلم وعلاقته بالتوجهات الهدفية

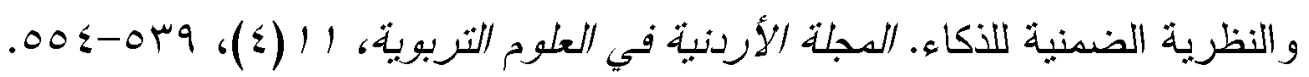

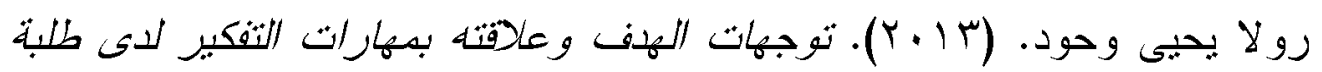
الدراسات العلبا بجامعة دمشق [رسالة ماجستير، كلية التربية، جامعة دمثق]. صادق كاظم جريو وزينب خضر كاظم. (Y (Y). توجهات أهداف الإنجاز و علاقتها بالانفتاح على الخبرة لدى طلبة جامعة بابل والجامعة الاسلامية. مجلة كلبة

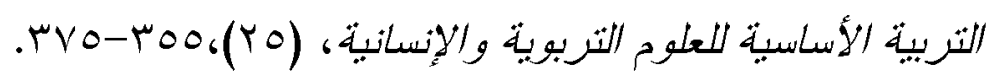


عبود جواد راضي. (10 ب). بناء وتطبيق مقياس نوجهات أهداث الإنجاز لاي طلبة الدراسة الاعدادية وفق نموذج برتنش الرباعي .لارك للفلسفة واللسانبات والعلوم الاجتماعية، (IV)، سبه

فتحي عبدالرحمن جروان. (T ( ب). تعلبم التفكبر: دفاهبم وتطبيقاث (ط9). دار الفكر للنشر والتوزيع. - مبن.

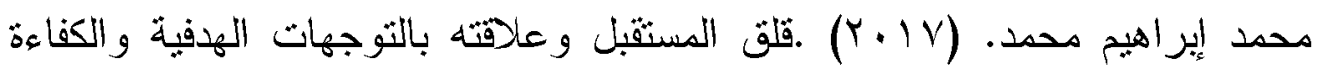

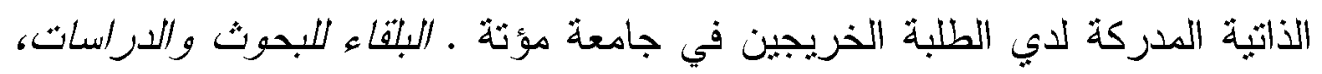
$. r 1-9 \cdot(r) r \cdot$

محمد سليمان الوطبان. (ب (Y). بنية نوجهات أهداف الإنجاز في ضوء النموذج الرباعي والنموذج السداسي لاى طلاب جامعة القصيم وطالباتها باستخدام النمذجة

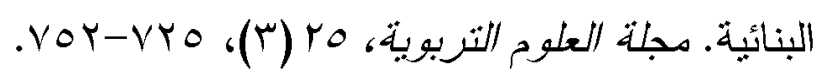

\section{References}

American Psychological Association. (2019). Publication Manual of the American Psychological Association ( $7^{\text {th }}$ ed.).

Ames, C., \& Archer, J. (1988). Achievement Goal in The Classroom: Students' Learning Strategies and Motivation Processes. Journal of Educational Psychology, 80(3), $260 \quad-267$.

Dweck , C., \& Leggett , E. (1988). A Social - Cognitive Approach to Motivation and Personality . Psychological Review , 95 , $256-$ 273.

Elliot, A . J. (1999).Approach and Avoidance Motivation and Achievement Goals. Educational Psychologist, 34 (3) $169-189$.

Elliot, A., \&Harackiewicz , J. M. (1996). Approach and Avoidance Achievement Goalsand Intrinsic Motivation : A Mediational Analysis. Journal of Personality and Social psychology , 70 (3) , $461-475$. 
Elliot, A., Murayama, K., Kobeisy, A., \&Lichtenfeld, S. (2015).Potential-Based Achievement Goals. British Journal of Educational psychology, 85 (2), 192-206.

Elliot, A., Murayama, K., \&Pekrun, R. (2011). A 3x2 Achievement Goal Model. Journal of Educational Psychology , 103 (3) , 632 648.

Elliott, C., \& Story, P. (2017). Motivational Effects Goal Orientation. The Kennesaw Journal of Undergraduate Research, 5(1), 1-18.

Gavaza, P., Muthart, T., \& Khan, G. (2014). Measuring Achievement Goal Orientations of Pharmacy Students. American Journal of Pharmaceutical Education, 78(3), Article 54, 1-6.

Hall, M., Hanna,L.,Hanna, A., \& Hall, K.(2015). Associations between Achievement Goal Orientations and Academic Performance Among Students at auk Pharmacy School . American Jornal of Pharmaceutical Education .79 (5).

Maehr, M., \&Zusho, A. (2009). Achievement Goal Theory: The Past, Present, and Future. Routledge Taylor \& Francis Group, 77-104.

Méndez-Giménez, A., Cecchini, J-A., Méndez-Alonso, D., Prieto, J-A., \&Fernández-Rio, J. (2018). Effect of $3 \times 2$ Achievement Goals and Classroom Goal Structures on Self Determined Motivation: a Multilevel Analysis in Secondary Education.Anales de Psicologi'a,34(1), 52-62.

Nicholls, J. (1984). Achievement Motivation : Conceptions of Ability, SubjectiveExperience, Task choice, and Performance, 9 (3), 328 346.

Ning, H. (2017). Factor Structure and Criterion Validity of Potential Based Achievement Goals : Evidence for a Bi factor Model . Journal of Psycho educational Assessment, (11).

Şahin, E.,Topkaya, N., \&Kürkçü, R. (2016). Sex and Age Differences in Achievement Goal Orientation in Turkish Adolescents. Journal of Education and Practice, 7(27), 149-156. 
Stan, A.,\&Oprea, C. (2015). Test anxiety and Achievement Goal Orientations of Students of Students at a Romanian University. Procedia-Social and Behavioral Sciences, (180), 1673-1679.

Was, C. (2006). Academic Achievement Goal Orientation: Taking Another Look. Electronic Journal of Research in Educational Psychology, (10), 529-550.

Was, C., \&Beziat, T. (2015). Exploring the Relationships between Goal Orientation, Knowledge and Academic Achievement. Journal Education and Human Development, 4(3), 67-77.

Wu, C. (2012). The Cross-Cultural Examination of 3x2 Achievement Goal Model in Taiwan. Procedia-Social and Behavioral Sciences, (69), 422-427. 